\title{
Thermal processing of kale purée: the impact of process intensity and storage on different quality related aspects
}

\author{
Scheling Wibowo ${ }^{a *}$, Adebayo Lateef Afuape ${ }^{a}$, Sofie de Man $^{b}$, Nathalie Bernaert ${ }^{b}$, Bart Van \\ Droogenbroeck $^{b}$, Tara Grauwet ${ }^{a}$, Ann Van Loey ${ }^{a}$, Marc Hendrickx ${ }^{a^{* *}}$
}

Authors are affiliated to:

aLaboratory of Food Technology, Leuven Food Science and Nutrition Research Center (LFoRCe), Department of Microbial and Molecular Systems ( $\left.\mathrm{M}^{2} \mathrm{~S}\right)$, KU Leuven, Kasteelpark Arenberg 22 box 2457, 3001 Heverlee, Belgium

https://www.biw.kuleuven.be/m2s/clmt/lmt/

bInstitute for Agricultural and Fisheries Research (ILVO), Technology and Food Sciences Unit (T\&V), Product Quality and Innovation (PI), Brusselsesteenweg 370, 9090 Melle, Belgium https://www.ilvo.vlaanderen.be/

* Corresponding author before publication

Telephone: +3216323648

Email: scheling@yahoo.com

** Corresponding author post-publication

Fax: +3216321960

Telephone: +3216321572

E-mail: marceg.hendrickx@kuleuven.be 


\section{ABSTRACT}

This study focused on investigating quality changes of thermally processed kale purée using an integrated targeted and untargeted approach. Low, medium, and high processing intensities (carried out at 70,90 , and $128{ }^{\circ} \mathrm{C}$ ) were selected based on predetermined shelf-life targets: frozen-thawed, refrigerated, and ambient storage, respectively. The results show that that physicochemical properties determining consumer acceptability were largely dependent on the treatment intensity. The high intensity treatment resulted in the least favorable quality characteristics (distinct brown color, chlorophyll and vitamin $\mathrm{C}$ destruction as well as a phase separation after storage). Enzymes were inactivated with increasing thermal load. Regarding taste related compounds, there was no clear effect of processing and storage on acidity and sugar profiles. The untargeted GC-MS approach showed that increasing the processing intensity resulted in an increase of the formation of furans and sulfides. Storage clearly affected the formation of volatiles that could be, depending on the thermal treatment, attributed to lipid and/or carotenoid oxidation, continuation of Maillard reactions, and enzyme catalyzed reactions.

\section{Industrial relevance}

Compared to other Brassicaceae vegetables such as as broccoli, cauliflower and different types of cabbages, kale so far has received little attention from an industrial processing point of view. However, kale has been reported to contain high nutritional value due to its important content of minerals, bioactive compounds and fibre. With the growing health awareness of consumers and increasingly busy lifestyles, the demand for more convenient fruit and vegetable products with high nutritional content has increased. Therefore, research to obtain more insight on the effect of processing and storage on kale purée is important.

\section{Keywords:}

Kale purée, thermal processing, storage, quality attributes, volatiles

\section{Highlights:}

- A combined targeted and untargeted approach is useful to obtain an integrated view on quality changes during processing and subsequent storage

- High-intensity thermal processing had the least favorable quality characteristics

- Low-intensity processing resulted in quality changes due to enzymatic reactions

- Enzymes can be inactivated by medium- and high-intensity thermal processing

- No significant impact of processing and storage on acidity and sugar content 


\section{INTRODUCTION}

Kale is a leafy green vegetable that belongs to the Brassicaceae family. It is usually harvested in the autumn and winter. Different kale cultivars adapted to various growing conditions are available. This vegetable is widely cultivated especially in central and northern Europe and North America (Schmidt et al., 2010). In recent years, kale has gained popularity especially among health-conscious consumers. Many studies have documented the nutritional and health benefits of kale. Kale is known for its high amount of essential minerals (especially $\mathrm{K}, \mathrm{Ca}, \mathrm{Mg}$, $\mathrm{Fe}$, and $\mathrm{Cu}$ ), bioactive compounds (such as vitamin C, carotenoids, chlorophyll, phenolics, and glucosinolates), and dietary fibre (Armesto, Gómez-Limia, Carballo, \& Martínez, 2018; Kim, Chiu, \& Ku, 2017; Korus, 2013; Šamec, Urlic, \& Salopek-Sondi, 2018).

Kale is predominantly sold fresh and, like most vegetables, it is highly prone to postharvest spoilage. Processing is one of the various possible technological means to significantly increase its shelf-life and make all-year availability possible. Also, processing increases its palatability and stability, adds product variety, increases nutrient availability and enhances income generation and drives value-addition (Augustin et al., 2016). Common processing techniques directed at long term preservation of kale involves blanching, canning, drying, and freezing (Korus, 2013). Moreover, its processing into convenience products such as chips, juices, fermented juices and inclusion into other fruit and vegetable beverages has been reported (Šamec et al., 2018). As for many other food products, thermal processing may result in significant losses of the nutritional value as well as induce detrimental changes to the sensorial attributes of the final products. Not to mention quality changes that develop during storage (Albanese, Russo, Cinquanta, Brasiello, \& Di Matteo, 2007; Bahçeci, Serpen, Gökmen, \& Acar, 2005). These can altogether influence the market value and reduce consumer acceptability (Armesto, Gómez-Limia, Carballo, \& Martìnez, 2017).

The objective of this study was to investigate quality changes in kale purée as affected by thermal processing and subsequent storage, in order to identify combinations of thermal processing and storage that allow a high quality product to reach the consumer. Based on predetermined targeted shelf-life conditions, three thermal processing intensities were applied: a low-intensity treatment (70 ${ }^{\circ} \mathrm{C}$ ) followed by long term frozen storage and subsequent thawing and a short two-day shelf-life under refrigerated conditions, a medium-intensity treatment $\left(90^{\circ} \mathrm{C}\right)$ for refrigerated storage during three weeks, and a high-intensity treatment $\left(128{ }^{\circ} \mathrm{C}\right)$ for long term ambient storage. Understanding food quality changes remains a challenge due to the fact that food products are complex systems in which multiple reactions can occur simultaneously either during processing or storage (Wibowo, Buvé, Hendrickx, Van Loey, \& Grauwet, 2018). Therefore, to assess the impact of these processes as well as the subsequent proposed storage, an integrated targeted and an untargeted analytical approach was followed.

In the first part of the research strategy, a targeted approach was selected to measure physicochemical properties determining the product appearance, texture, and taste. These attributes are important since changes in the sensorial attributes of the final products can influence the consumer perception and buying preferences. In the second part, an untargeted fingerprinting approach which explores the 
overall process and storage impacts on the products was performed by studying the volatile fraction in the product headspace. Volatile and semi-volatile compounds are often associated with known chemical reactions such as Maillard reaction, caramelization, Strecker degradation, nutrient degradation, etc. This can provide further insights into the different process and/or storage induced phenomena occurring in foods (Grauwet, Vervoort, Colle, Van Loey, \& Hendrickx, 2014).

\section{MATERIALS AND METHODS}

\subsection{Kale purée processing}

Around $450 \mathrm{~kg}$ of curly kale (Brassica oleracea L.) was purchased from a supplier in Poland and a local supplier. The material (a mix of the two batches) was stored in a cold room $\left(4^{\circ} \mathrm{C}\right)$ before processing. Frozen raw material was used as a starting point to represent the current industrial practices. Kale leaves were transferred into an integrated cutting, mixing and cooking machine (Seydelmann, Stuttgart, Germany) set at a rotational speed of $6000 \mathrm{rpm}\left(25^{\circ} \mathrm{C}\right)$. Subsequently, the mashed kale was transferred into a single stage spiral-filter press (VaculIQ 1000, VacullQ, Hamminkeln, Germany) for extraction under vacuum. In the extraction cell, a plastic spiral rotates within a cylindrical filter element of $1000 \mu \mathrm{m}$. A feed pump frequency $20 \%$, spiral frequency $100 \%$, vacuum pump frequency $100 \%$, and 4 channels of the spiral with a shaft inclination of $38^{\circ}$ was applied. During the extraction process, kale pulp was ejected at the top of the spiral. All processing steps were performed in the Food Pilot (Melle, Belgium).

\subsubsection{Thermal processing (TP) treatment}

The fresh kale purée was then thermally treated in a multipurpose UHT pilot plant unit (APV SPP, SPX Corporation, Gatwick, United Kingdom). Depending on the targeted shelf-life period, kale purée was treated under different temperature intensities: A low intensity $70{ }^{\circ} \mathrm{C}$ for $120 \mathrm{~s}$ for frozen storage followed by thawing and a two day storage under refrigerated conditions (TP70), a medium intensity $90{ }^{\circ} \mathrm{C}$ for $75 \mathrm{~s}$ for refrigerated storage (TP90), and a high intensity $128{ }^{\circ} \mathrm{C}$ for $75 \mathrm{~s}$ for ambient storage (TP128). Kale purée was preheated to $65^{\circ} \mathrm{C}$, then heated to the required temperature and held at this temperature for the required time. In the next step, the purée was cooled to $65{ }^{\circ} \mathrm{C}$ and subsequently to $4{ }^{\circ} \mathrm{C}$. All heating and cooling steps were performed via an indirect tubular heat exchanger. Subsequently, treated kale purée was manually transferred into sterile high density polyethylene (HDPE) bottles and heat sealed with aluminum foil. The filling process was conducted under aseptic conditions in a laminar air flow cabinet.

\subsubsection{Storage and sampling}

Untreated samples were stored at $-40{ }^{\circ} \mathrm{C}$ serving as the control samples. All treated samples were stored, storage conditions being dependent on the processing intensities used. After storage (TP70 at $20{ }^{\circ} \mathrm{C}$ for 3 months and 2 days at $4{ }^{\circ} \mathrm{C}$, TP90 at $4{ }^{\circ} \mathrm{C}$ for 3 weeks and TP128 at ambient conditions for 3 months), samples were taken randomly, transferred into smaller tubes and frozen in liquid nitrogen before storage at $-40^{\circ} \mathrm{C}$. Prior to analyses, sample tubes were thawed in a circulating water bath at 25 
${ }^{\circ} \mathrm{C}$. After treatments and during storage, the microbiological load (Listeria spp, Listeria monocytogenes, Enterobacteriaceae, total aerobic and anaerobic mesophilic bacteria, lactic acid bacteria, aerobic and anaerobic sporeforming bacteria, yeasts and molds) was evaluated to ensure the microbial quality of the samples. Results showed that all treatments were capable of inactivation Listeria spp and Listeria monocytogenes present. Severe treatment at $128{ }^{\circ} \mathrm{C}$ is capable to inactivate spores as well as enzymes (for microbial data see Supplementary material 1, for enzymes see further).

\subsection{Targeted quality analyses}

\subsubsection{Color measurement}

Color was measured using a UV-Vis spectrophotometer (Sensing Unveils CM-5, Konica MinoltaSensing, Osaka, Japan). Samples were filled into a glass cylindrical container and the measurements were performed in triplicate with three readings for each sample. The CIE color coordinates $L^{*}, a^{*}$, and $b^{*}$ components were recorded. The $L^{*}$ value is a measure of the lightness, the $a^{*}$ value of the greennessredness and the $b^{*}$ value of the blueness-yellowness. Total color difference, $\Delta E^{*}$, was calculated using Hunter-Scotfield's equation:

$$
\Delta E^{*}=\sqrt{\left[\left(L^{*}-L_{0}^{*}\right)^{2}+\left(a^{*}-a_{0}^{*}\right)^{2}+\left(b^{*}-b_{0}^{*}\right)^{2}\right]}
$$

Perceivable color differences can be classified as not noticeable (0-0.5), slightly noticeable (0.5-1.5), noticeable (1.5-3.0), well visible (3.0-6.0) and great (>6.0).

\subsubsection{Chlorophyll determination}

Total chlorophyll, chlorophyll $a$ and chlorophyll $b$ were determined according to the procedure of Armesto et al. (2017) with some modifications. Kale purée $(0.26 \mathrm{~g})$ was homogenized in $10 \mathrm{~mL}$ of acetone $(80 \% \mathrm{v} / \mathrm{v})$ using a vortex mixer. The mixture was then centrifuged at $4000 \times \mathrm{g}$ for $5 \mathrm{~min}\left(4{ }^{\circ} \mathrm{C}\right)$, the residue was re-extracted two times under the same conditions and the resulting supernatants were combined and filtered through a syringe filter. The total chlorophyll, chlorophyll $a$ and chlorophyll $b$ content were measured at 645 and $663 \mathrm{~nm}$ using a spectrophotometer (Ultrospec 2100 pro, Amersham Biosciences) and calculated according to Albanese et al. (2007):

$$
\text { Chlorophyll a }(\mathrm{mg} / \mathrm{g})=\frac{12.7 A_{663}-2.69 A_{634} \times m l \text { Acetone }}{m g}
$$

$$
\text { Chlorophyll } b(\mathrm{mg} / \mathrm{g})=\frac{22.9 A_{645}-4.68 A_{663} \times m l \text { Acetone }}{m g}
$$

$$
\text { Total chlorophyll }(\mathrm{mg} / \mathrm{g})=\text { chlorophyll } a+\text { chlorophyll } b
$$

where $A_{645}$ and $A_{663}$ represents value of absorbance at 645 and $663 \mathrm{~nm}$, respectively. 
The particle size distribution (PSD) was measured using a laser diffraction particle size analyzer (LS 13320, Beckman Coulter Inc., Brea, CA) equipped with a Universal Liquid Module. A few drops of the samples were poured into a stirring-tank filled with demineralized water until a polarization intensity differential scattering (PIDS) obscuration of $40 \%$ was reached. The diluted sample was pumped into a measuring cell where the laser light, with a wavelength of the main illumination source at $750 \mathrm{~nm}$ and wavelengths of halogen light for PIDS $450 \mathrm{~nm}, 600 \mathrm{~nm}$ and $900 \mathrm{~nm}$, was scattered by the particles. The intensity of the scattered laser light is detected and analyzed by the Fraunhofer model. The particle sizes were described using $D[v, 0.1], D[v, 0.5]$ and $D[v, 0.9]$ values, which indicate the particle diameter at which 10,50 and 90 vol\% of the particles have a smaller diameter, respectively.

\section{1}

\subsubsection{Bostwick consistency}

The flow behavior of kale purée was evaluated using an empirical Bostwick consistency test (CSC Scientific Company, VA, USA). The purée was placed into the consistometer reservoir and after an equilibration time of $1 \mathrm{~min}$, purée was allowed to flow under its own weight along a level surface for $30 \mathrm{~s}$ at room temperature. The Bostwick consistency index is the distance travelled expressed in centimeters by the purée. During this measurement phase separation of the particle fraction and the serum was evaluated. All measurements were performed in duplicate.

\subsubsection{Enzyme activity measurements}

\subsubsection{Polyphenol oxidase (PPO) activity}

Kale purée $(0.5 \mathrm{~g})$ was homogenized with $5 \mathrm{~mL}$ of $0.2 \mathrm{M}$ sodium phosphate buffer $(\mathrm{pH} 6.5)$ containing $1.2 \mathrm{M} \mathrm{NaCl}$ and $1 \%$ polyvinylpyrrolidone (PVPP) by stirring for $10 \mathrm{~min}$ at $4{ }^{\circ} \mathrm{C}$. The mixture was filtered through a cheese cloth followed by centrifuging the filtrate at $16,000 \times g$ for 15 min $\left(4{ }^{\circ} \mathrm{C}\right.$ ) (Microfuge $22 \mathrm{R}$, Beckman Coulter, Fullerton, CA, US). The supernatant was collected as crude PPO extract and used for activity measurement. The extraction was carried out in triplicate. The activity was measured using $0.2 \mathrm{~mL}$ of PPO extract and $2.8 \mathrm{~mL}$ of substrate solution (catechol $0.05 \mathrm{M}$ in $0.2 \mathrm{M}, \mathrm{pH} 6.5$ sodium phosphate buffer solution). The absorbance of the compound was measured in a spectrophotometer (Ultrospec 2100 pro, Amersham Biosciences) at $420 \mathrm{~nm}\left(25^{\circ} \mathrm{C}\right)$. The activity was estimated from the slope which constitute the linear section of the curve of absorbance against reaction time. The percentage of residual enzyme activity was estimated with the following equation:

$$
\text { Residual activity }(R A)=\frac{A_{t}}{A_{0}} \times 100
$$

with $A_{t}$ and $A_{0}$ representing the enzyme activities of treated and untreated (control) samples, respectively.

\subsubsection{Peroxidase (POD) activity}

POD was extracted by mixing $0.5 \mathrm{~g}$ purée with $5 \mathrm{~mL}$ of $0.2 \mathrm{M}$ sodium phosphate buffer ( $\mathrm{pH} 6.5$ ) which contains $1 \mathrm{M} \mathrm{NaCl}$ and $1 \%$ PVPP for $10 \mathrm{~min}$ at $4{ }^{\circ} \mathrm{C}$. The homogenized solution was filtered using a cheese cloth followed by centrifugation at $16000 \times \mathrm{g}$ for $15 \mathrm{~min}\left(4^{\circ} \mathrm{C}\right)$. The extraction was carried out in 
triplicate. POD activity was determined by using $0.2 \mathrm{~mL}$ of the extract and $2.8 \mathrm{~mL}$ of substrate solution (0.2 M sodium phosphate buffer $(\mathrm{pH} 6.5), 0.3 \%(\mathrm{w} / \mathrm{v})$ o-phenylenediamine and $0.1 \%(\mathrm{v} / \mathrm{v})$ hydrogen peroxide). The activity was measured immediately using a spectrophotometer at $485 \mathrm{~nm}\left(25^{\circ} \mathrm{C}\right)$. The residual activity was determined by using Equation 5.

\subsubsection{Pectin methylesterase (PME) activity}

Pectin methyl esterase activity was determined according to the procedure of Vervoort et al. (2011). For measurement of the PME activity, $1 \mathrm{~mL}$ of purée was added to $30 \mathrm{~mL}$ of a $0.35 \%(\mathrm{w} / \mathrm{v})$ apple pectin solution containing $0.117 \mathrm{M} \mathrm{NaCl}$ incubated at $22{ }^{\circ} \mathrm{C}$. The $\mathrm{pH}$ of the system was maintained at $\mathrm{pH} 7$ by constant addition of $0.01 \mathrm{~N} \mathrm{NaOH}$ during the enzymatic reaction. The percentage of relative activity of all the analyzed enzymes was calculated by Equation 5. The measurements were taken in duplicates.

\subsection{6 $\mathrm{pH}$ and organic acid profile determination}

The $\mathrm{pH}$ was measured in triplicate using a pH meter (Meterlab PHM210, Radiometer Analytical, Villeurbanne, France).

Organic acids were extracted and quantified according to the procedure of Wibowo et al. (2015). Ten $\mathrm{mL}$ of purée was mixed with $500 \mu \mathrm{L}$ of Carrez I (15\% w/v K4[Fe (CN)6]) and Carrez II (30\% w/v ZnSO4). After $30 \mathrm{~min}$ of rest, the mixture was centrifuged at $24,000 \times \mathrm{g}$ for $15 \mathrm{~min}\left(4^{\circ} \mathrm{C}\right)$. The supernatant was filtered through a syringe filter (Chromafil A-45/25, Macherey-Nagel, Düren, Germany) and $2 \mu \mathrm{l}$ of the filtrate was injected into a RP-HPLC (Agilent 1200 series, Diegem, Belgium). Organic acids were separated on a Prevail Organic Acid column $(250 \mathrm{~mm} \times 4.6 \mathrm{~mm}, 5 \mu \mathrm{m}$ particle size, Alltech Grace, Deerfield, USA) coupled with a guard cartridge using isocratic elution $(25 \mathrm{mM}$ potassium dihydrogen phosphate buffer $\mathrm{pH} 2.5)$ at $1 \mathrm{~mL} / \mathrm{min}\left(25^{\circ} \mathrm{C}\right)$. The system was equipped with a UV-DAD detector set at $210 \mathrm{~nm}$. All samples were analyzed in triplicate. Identification and quantification were performed based on retention times and a calibration curve of standard solutions.

\subsubsection{Total soluble solid and sugar profile determination}

Total soluble solids content, expressed as ${ }^{\circ}$ Brix, were measured in triplicate using a digital refractometer (RX-7000 $\alpha$, Atago, Tokyo, Japan) at $20^{\circ} \mathrm{C}$.

The sugar profiles were determined using a HPLC system (Agilent 1200 series, Diegem, Belgium) coupled with evaporative light scattering detection (Alltech 3300 ELSD, Grace, Deerfield, IL, USA). The extraction procedure of sugars was analogous to the organic acid analysis. Five microliters of a 10 -fold dilution of the extract was injected into the HPLC system. Separation was performed on a Prevail carbohydrate ES column ( $250 \mathrm{~mm} \times 4.6 \mathrm{~mm}, 5 \mu \mathrm{m}$ particle size, Alltech Grace, Deerfield, USA) protected with a guard cartridge. An isocratic elution with $75 \%(\mathrm{v} / \mathrm{v})$ acetonitrile/water at a flow rate of $1 \mathrm{~mL} / \mathrm{min}$ was used. The column was maintained at $30^{\circ} \mathrm{C}$. For identification, retention times were compared with glucose monohydrate, fructose, and sucrose standard solutions. For quantification, calibration curves of standard solutions were used. Sugar analyses were carried out in triplicate.

\subsubsection{Vitamin C determination}

The determination of total vitamin C was carried out according to the method by Wibowo et al. (2015). Both ascorbic acid (AA) and dehydroascorbic acid (DHA) were extracted by adding $15 \mathrm{~mL}$ of extraction 
buffer ( $1 \% \mathrm{w} / \mathrm{v}$ meta-phosphoric acid with $0.5 \%$ oxalic acid adjusted to $\mathrm{pH} 2.0$ ) into $5 \mathrm{~g}$ of kale purée. The mixture was centrifuged for $15 \mathrm{~min}$ at $24,000 \times \mathrm{g}\left(4^{\circ} \mathrm{C}\right)$, subsequently, the supernatant was filtered through a syringe filter and stored at $-80^{\circ} \mathrm{C}$. Five $\mathrm{mL}$ of the extracts was adjusted to $\mathrm{pH} 3.5$ and then divided into two parts. For the determination of $A A$ content, $1 \mathrm{~mL}$ of the $\mathrm{pH}$-adjusted supernatant was diluted in phosphate buffer $\left(20 \mathrm{mM} \mathrm{NaH}_{2} \mathrm{PO}_{4}+1 \mathrm{mM} \mathrm{Na}{ }_{2} \mathrm{EDTA}, \mathrm{pH} 3.5\right)$. To determine the DHA content, $1 \mathrm{~mL}$ of the $\mathrm{pH}$-adjusted supernatant was mixed with $2 \mathrm{~mL}$ reducing agent TCEP $(2.5 \mathrm{mM}$ tris (2carboxyl-ethyl) phosphine in phosphate buffer, pH 3.5). After a centrifugation step at $19,900 \times g$ for 15 min $\left(23^{\circ} \mathrm{C}\right)$, the supernatant was filtered through a syringe filter before injection to RP-HPLC (DionexBioLC, Sunnyvale, CA). The DHA content was calculated by subtracting the total vitamin $\mathrm{C}$ content with the AA content. The mobile phase ( $1 \mathrm{mM} \mathrm{Na}_{2}$ EDTA and $10 \mathrm{mM} \mathrm{CH}_{3} \mathrm{COONH}_{4}$ ) was pumped at $0.8 \mathrm{~mL} / \mathrm{min}$. A $25-\mu \mathrm{L}$ injection volume was used and the separation occurred at $25{ }^{\circ} \mathrm{C}$ in a prevail $\mathrm{C}_{18}$ column coupled to corresponding guard column. Detection was performed at $245 \mathrm{~nm}$. The AA content was quantified based on a calibration curve using an external standard solution of AA (99\% Acros organics, Geel, Belgium) in extraction buffer. All measurements were done in triplicate.

\subsection{Headspace solid-phase microextraction-gas chromatography-mass spectrometry (HS-SPME-GC- MS) analysis}

203

204

205

206

207

208

209

210

Kale purée $(1.5 \mathrm{~g}$ ) and saturated $\mathrm{NaCl}$ solution $(1.5 \mathrm{~mL}$ ) were pipetted into an amber glass vial (10 $\mathrm{mL}$, VWR International, Radnor, PA, USA). The vials were tightly closed using screw caps with silicone septum seal (GRACE, Columbia, MD, USA), mixed, and placed in the cooling tray of the autosampler which was maintained at $10^{\circ} \mathrm{C}$. The headspace analyses were performed on a gas chromatography (GC) system (7890N, Agilent technologies, Diegem, Belgium) coupled to a mass selective detector (MSD) (5977N, Agilent Technologies, Diegem, Belgium) and equipped with a CombiPAL autosampler (CTC analytics, Zwingen, Switzerland).

The juices were equilibrated for $20 \mathrm{~min}$ at $30{ }^{\circ} \mathrm{C}$ under agitation at $500 \mathrm{rpm}$. Volatiles were extracted at $30{ }^{\circ} \mathrm{C}$ for $10 \mathrm{~min}$ using a SPME fiber coated with 30/50 $\mu \mathrm{m}$ divinylbenzene/carboxen/ polydimethylsiloxane (DVB/CAR/PDMS) (StableFlex, Supelco, Bellefonte, PA, USA). Afterwards, the volatiles were desorbed at $230^{\circ} \mathrm{C}$ for $2 \mathrm{~min}$ and injected into the $\mathrm{GC}$ system in $1 / 5$ split mode. Compound separation occurred on a HP-INNOWax capillary column $(60 \mathrm{~m} \times 0.25 \mathrm{~mm}$ i.d., $0.25 \mu \mathrm{m}$ film thickness, Agilent Technologies, Santa Clara, CA, USA) with helium as a carrier gas at $1.27 \mathrm{~mL} / \mathrm{min}$. The GC-oven temperature was programmed from a starting temperature of $40^{\circ} \mathrm{C}$, which was maintained for $2 \mathrm{~min}$. The temperature was further increased to $120^{\circ} \mathrm{C}$ at $4{ }^{\circ} \mathrm{C} / \mathrm{min}$, to $200{ }^{\circ} \mathrm{C}$ at $7{ }^{\circ} \mathrm{C} / \mathrm{min}$, and finally ramped at $50{ }^{\circ} \mathrm{C} / \mathrm{min}$ to $250^{\circ} \mathrm{C}$ and kept for $2 \mathrm{~min}$ before cooling back to $40{ }^{\circ} \mathrm{C}$. The ion source and quadrupole temperatures of MS were 230 and $150^{\circ} \mathrm{C}$, respectively. During the analysis, the samples were randomized as a function of treatment per storage time. The volatile analyses of each sample at each storage moment were repeated six times.

\subsection{Data analysis}

The data obtained from the targeted analyses (physicochemical properties and enzyme activities) were analyzed by JMP software (JMP Pro 13.1 statistical software, SAS Institute, Chicago, IL). One-way analysis of variance (ANOVA) and Tukey's post-hoc test at 95\% confidence level were performed to test for significant differences among treatments stored and non-stored samples. The volatile compounds 
were investigated by the untargeted approach with subsequent dataset analyzed by multivariate data analysis MVDA (section 2.5) and resulting differences in treatments and storage by Tukey post hoc test.

\subsection{Data pre-processing and multivariate data analysis (MVDA)}

The obtained GC-MS total ion chromatograms were analyzed with an automated mass spectral deconvolution and identification system (AMDIS) (Version 2.72, 2014, National Institute of Standards and Technology, Gaithersburg, MD, USA) to extract "pure" component spectra from complex chromatograms. In a subsequent step, the deconvoluted mass spectra were analyzed with the Mass Profiler Professional (MPP) (Version 12.0, 2012, Agilent Technologies, Diegem, Belgium) software for filtering and peak alignment. Data pre-processing by MPP generated a data table combining the information on peak area for each peak detected in each sample, which was used as an input for MVDA (Solo Version 8.5.2, 2017, Eigenvector Research, Wenatchee, WA). To asses all data and to identify possible outliers, first, principal component analysis (PCA) was conducted. Subsequently, partial least squares discriminant analysis (PSL-DA) was performed to determine which volatile compounds were important for class separation. Three research questions were investigated by PLSDA: (i) what is the impact of kale purée treatment and storage, in particular in terms of differences in volatiles compounds and their concentrations; (ii) what is the impact of the different thermal processing intensities (TP70, TP90 and TP128); (iii) what is the impact of storage conditions used. In these evaluations, the volatiles were considered as $X$-variables and, depending of the effect studied, untreated (control) and thermal processing (TP) treatments before and after storage as categorical $Y$ variables. The multivariate model with the lowest number of latent variables (LVs) resulting in class separation was selected. A score plot and a correlation loading plot were combined in a bi-plot, which was constructed using OriginPro 8 (Origin Lab Corporation, Northampton, MA, USA). To quantitatively select discriminant headspace volatile compounds and to evaluate their significance for class differentiation, Variable Identification (VID) coefficients were determined. Volatiles with an absolute VID coefficient higher than 0.80 were considered important (i.e. markers) and were further identified by comparing the deconvoluted mass spectrum with the reference mass spectra from NIST spectral library (NIST14, version 2.2, National Institute of Standards and Technology, USA) and Wiley spectral library (Wiley 2010, version 9, USA). Compounds with a match and reverse match of above $80 \%$ in combination with visual inspection, were accepted.

\section{RESULTS AND DISCUSSIONS}

\subsection{Evaluating the impact of treatment and storage on quality attributes of kale purée: a targeted} approach

\subsubsection{Impact on color related attributes}

\subsubsection{Color and total chlorophyll content}

Changes in the color of kale purée after processing and storage were measured and expressed in CIELAB coordinates (Table 1 ). All treatments resulted in a significant increase in $L^{*}$ and $a^{*}$ values compared with the control sample $(p<0.05)$ indicating lighter and more reddish/less greenish color 
shades compared to the control sample. On the contrary, $b^{*}$ values (blueness-yellowness) were shown to decrease as the process intensity increases. Armesto et al. (2017) reported a decrease in yellowness $\left(b^{*}\right)$ and in greenness $\left(-a^{*}\right)$ in kale after boiling and vacuum cooking treatments which may be caused carotenoid and chlorophyll degradation. However, in contrast to this study, they observed a decrease in lightness after these treatments.

The perceived colour changes between the processed/stored samples and the control sample (i.e. the untreated sample before storage) are represented by the total colour difference $\left(\Delta E^{*}\right)$. Similar to the trend in $a^{*}$ values, the $\Delta E^{*}$ values increased after processing. The high-intensity treatment (TP128), resulted in the highest $\Delta E^{*}$ value which depicts a great visible difference $\left(\Delta E^{*}>6.0\right)$. For vegetable products, the green color is reported to depend on the level and relative proportion of chlorophyll $a$ and $b$ (Korus, 2013). Thus, this change results from the conversion of green colored chlorophylls $a$ and $b$ to olive brown pheophytin $a$ and $b$ and then into olive brown pyropheophytin $a$ and $b$ due to the high temperature and time of processing (Weemaes, Ooms, Van Loey, \& Hendrickx, 1999). Indeed, TP128 purée had the lowest total chlorophyll, chlorophyll $a$ and $b$ contents (Table 1 ) and had distinct brownish color (Supplementary material 2). This sample retained only $40 \%$ of the total chlorophyll present in the fresh untreated sample. TP70 and TP90 treatments maintained the green color of the purées better than TP128, with $82 \%$ and $85 \%$ total chlorophyll retention, respectively. Similar to the total chlorophyll content changes, all treatments caused a significant reduction in chlorophyll $a$ compared with the untreated sample. Whereas, TP70 and TP90 resulted in a non significant difference in chlorophyll $b$ compared to the untreated sample. This observation showed that the extent of chlorophyll $a$ degradation is larger than that of chlorophyll $b$ when subjected to the same heat intensity. This was also reported in broccoli juice (Weemaes et al., 1999) and kale (Armesto et al., 2017).

During storage, the $L^{*}$ and $b^{*}$ values decreased in all samples indicating darker color and reduced yellowness. Storage also caused significant decreases in greeness (- $a^{*}$ value) which is consistent with the observed decreases in total chlorophyll contents of all samples. As observed, $\Delta E^{*}$ increased with time despite the differences in storage temperature (Table 1). Armesto et al. (2017) observed similar trends for $L^{*}, a^{*}, \Delta E^{*}$ values, and total chlorophyll content of vacuum-cooked kale samples during 21 days of refrigerated storage. It is likely that chlorophylls continued to degrade during storage as the conversion of chlorophyll into pheophytins can even occur even under frozen conditions (Martins \& Silva, 2002). In addition, in the case of the TP70 sample, the thermal treatment applied may not be adequate to completely inactivate chlorophyllase and lipoxygenase. For this treatment, enzymatic conversions therefore can be expected during the thawing and refrigerated storage we applied to these samples. Chlorophyllase catalyzes the conversion of chlorophylls to chlorophyllides and pheophythins to pheophorbides whereas lipoxygenase is responsible for coupled oxidation reactions of unsaturated lipids and chlorophylls leading to chlorophyll bleaching (Weemaes et al., 1999; Gökmen, Savas Bahçeci, Serpen, \& Acar, 2005). Besides degradation of chlorophyll, other possible reactions linked to color changes are enzymatic browning, Maillard-associated reactions, carotenoid degradation as well as ascorbic acid degradation reaction formed brown compounds (Korus, 2013; Wibowo et al., 2015). 


\subsubsection{Polyphenol oxidase (PPO) and peroxidase (POD) activities}

All treatments resulted in a significant reduction in PPO activity compared with the untreated purée ( $p$ $<0.05$ ), see Figure 1. The low-intensity treatment TP70 showed a higher residual enzyme activity (RA 55\%) compared to sample treated at $90{ }^{\circ} \mathrm{C}$ (RA 5\%). On the contrary, the treatment at $128{ }^{\circ} \mathrm{C}$ brought about almost complete PPO inactivation (RA<1\%). This is consistent with the findings of Rayan and colleagues (2011) who reported that the rate of PPO inactivation in cauliflower is dependent on temperature and increasing inactivation was observed with increasing temperature ranging from 50 to $100{ }^{\circ} \mathrm{C}$ at $5{ }^{\circ} \mathrm{C}$ intervals. At temperature above $85{ }^{\circ} \mathrm{C}$, PPO, as well as pectin methylesterase and ascorbic acid oxidase (AAO) were completely inactivated. During storage, the PPO activity tends to decrease which can be attributed to the oxidation of phenolic compounds where the oxidized products could inhibit PPO activity (López-Serrano \& Ros Barceló, 2002).

The residual POD activity as a function of the different processing intensities was observed to follow the same trend as PPO. The notable difference, however, is that the residual POD activity the same processing intensity is higher (e.g. RA $\sim 70 \%$ for TP70) than the corresponding PPO activities which agrees with the fact that POD is more thermostable than PPO although this depends on the matrix (Terefe, Buckow, \& Versteeg, 2014). After storage, there were no clear changes in POD activity for all treated samples. In a study conducted by Gökmen et al. (2005) on peas, 25\% POD inactivation was achieved after blanching at $70^{\circ} \mathrm{C}$ for $4 \mathrm{~min}$, while blanching at $80^{\circ} \mathrm{C}$ for $2 \mathrm{~min}$ was sufficient to inactivate POD ( $\sim 90 \%$ inactivation). They reported that during 12 months of frozen storage at $-18{ }^{\circ} \mathrm{C}$, POD activity of the thermally-treated peas continued to decrease. The presence of residual POD and PPO activity in processed vegetable products in many cases, has been linked with the formation of offflavors and discoloration through the catalysis of oxygenation reactions and oxidation of phenolics. Also, POD and PPO have some synergistic activities which can be detrimental for quality preservation (Terefe et al., 2014).

\subsubsection{Vitamin C}

The changes in total vitamin $C$ content as well as the proportion of AA and DHAA after both processing and storage are illustrated in Figure 1. The average total vitamin $C$ content of the untreated kale purée was $181.83 \mathrm{mg} / \mathrm{kg}$ purée with absolute contribution of DHAA as no AA was present. This could be attributed to possible conversion of all AA to DHAA due to enzymatic conversion by AAO and ascorbic acid peroxidase since no heat treatment was applied (Munyaka, Makule, Oey, Van Loey, \& Hendrickx, 2010). Munkaya et al. (2010) reported similar observations whereby AAO was able to oxidize all the AA in untreated crushed broccoli to DHAA.

With respect to the processed samples, all treatments resulted in substantial loss of vitamin C (84-94\%), depending on the treatment intensity. This is consistent with Davey et al. (2002) where AA losses of over $50 \%$ have been reported to be typical for vegetable products due to processing. A relative high vitamin C loss in the TP70 sample could be due to the low thermal load which is insufficient to rapidly inactivate the $A A O$ and the low temperature and long-time regime, both of which can facilitate AA oxidation to DHAA and further hydrolysis to diketogulonic acid and other degradation products with no vitamin C activity (Verbeyst, Bogaerts, Van der Plancken, Hendrickx, \& Van Loey, 2013). As expected, the TP128 purée showed the highest vitamin C loss with only $6 \%$ retention. Severe thermal treatment 
has been linked with rapid degradation of $A A$ to various degradation products since it can accelerate the rate of DHAA and AA degradation (Verbeyst et al., 2013).

As shown in Figure 1, a further decrease in vitamin $\mathrm{C}$ of all samples occurred during storage. For most samples, at the end of storage, the levels of vitamin $\mathrm{C}$ were below the detection limit (LOD $=1.8 \mathrm{mg} / \mathrm{L}$ ), except for TP70 with 2\% retention. It is clear that (pre)treatment plays a substantial role in the AA and vitamin $\mathrm{C}$ losses. Moreover, several factors such as possible presence of oxygen, metal ions, light, enzymes, and radicals can cause AA degradation in the samples during processing and storage (Davey et al., 2002; Verbeyst et al., 2013).

\subsubsection{Impact on textural related attributes}

\subsubsection{Particle size distribution and Bostwick consistency}

Figure 2 presents the effect of processing and storage on the PSD and the Bostwick consistency. Based on the assumption that the particles are spherical, specific diameters such as the D10, D50 and D90 were presented in Supplementary material 3. It was observed that all samples showed an almost monomodal distribution with median particle size, expressed as D50, ranged from 300 to $430 \mu \mathrm{m}$. The TP128 sample showed the highest particle sizes which could be linked with the fact that the more severe heat treatment is capable of inducing the solubilization of cell wall and middle lamella polymers leading to higher mechanical disruption to bring about particles ranging from cell fragments to cell clusters. Treatments at 70, 90, and $128{ }^{\circ} \mathrm{C}$ provoked significant reductions in Bostwick consistency index $(p<0.05)$ with no significant differences among these treatments (Figure 2). Low consistency indices indicate more consistent purées which have higher resistance to flow than the untreated sample.

Storage conditions at ambient, refrigerated and frozen temperatures did not influence he particle sizes and the consistency values. However, a separation between serum and pulp was observed, in particular for higher intensity processed samples (figure not shown). As the PSD did not vary significantly changes in the purée serum may explain the changes in consistency. The high thermal load may solubilize and leach cell wall polymers especially pectin from the middle lamella and primary cell walls into the purée serum through $\beta$-elimination reaction (Van Buggenhout, Sila, Duvetter, Van Loey, \& Hendrickx, 2009). This is likely the case since the $\mathrm{pH}$ of the kale purées $(\mathrm{pH}>5)$ and temperature of treatment are within the range of $\beta$-elimination reaction. This was also observed during severe heat treatment of carrot pieces (Moelants et al., 2013).

\subsubsection{Pectin methylesterase (PME) activity}

PME by its action on pectin, leads to textural, viscosity and cloud stability changes in fruit and vegetable products (Moelants et al., 2013). For this reason, the effect of thermal processing on inactivating the enzyme was studied. As seen in Figure 2, PME was completely inactivated by TP90 and TP128. The low-intensity TP70 resulted in about 10\% residual enzyme activity that further decreased during storage. Previous studies have reported the effect of thermal treatments on PME inactivation in fruit and vegetable juices. Our results agree with the study of Vervoort et al. (2011) who reported that 
mild heating $\left(72^{\circ} \mathrm{C} / 20 \mathrm{~s}\right)$ was unable to completely inactivate orange juice PME (RA $=92 \%$ ). For carrot pieces, a temperature of $95^{\circ} \mathrm{C}$ for 5 min can inactivate the enzyme (Moelants et al., 2013).

\subsubsection{Impact on taste related attributes: organic aced and sugar profile}

The results on the $\mathrm{pH}, \mathrm{TSS}$, organic acid and sugar profile of the untreated and processed samples are shown in Table 1. Compared to the control, there was no clear effect of processing on the $\mathrm{pH}$ of kale purées $(p>0.05)$. Soluble solids content of the processed samples ranging from 10.13 to 10.59 were all significantly lower than that of the untreated sample (12.33). Oxalic, malic and citric acid are the major organic acids found in all samples accounting for $59 \%, 28 \%$, and $13 \%$ of the total organic acids, respectively. The presence of oxalic acid in green vegetables including kale is reported by Armesto et al. (2018). For the oxalic and citric acid content, there was a slight change for processed samples compared to the control sample; however, the malic acid content remained stable after processing.

All samples had levels of fructose about $36 \%$ of the total sugars, followed by glucose and sucrose with around $33 \%$ and $30 \%$, respectively (see Table 1 ). Little differences in total sugar and individual sugar contents were observed in the different treated samples. In Brassica vegetables, the presence of free sugars can reduce the bitter taste which attributed to specific glucosinolates (e.g. sinigrin and glucobrassicin), and glucosinolates hydrolytic products (e.g. isothiocyanates) (Bell, Oloyede, Lignou, Wagstaff, \& Methven, 2018; Engel, Baty, le Corre, Souchon, \& Martin, 2002).

After storage, ${ }^{\circ}$ Brix values, individual sugar, individual acid, total sugar and total acid contents did not change significantly or in other words the acidity and sweetness of the purées remained stable in the range of storage time and temperature conditions studied.

\subsection{Evaluating the impact of treatment and storage on volatiles of kale purée: an untargeted GC-MS fingerprinting approach}

The volatiles of untreated (control) and thermally processed (TP70, TP90 and TP128) kale purées were fingerprinted using a HS-SPME-GC-MS method. A representative total ion chromatogram of the headspace fingerprint of fresh untreated purée was depicted in Supplementary material 4. On average 109 volatile compounds were detected in the headspace of the fresh sample. The two most abundant peaks were identified as dimethyl trisulfide and allyl isothiocyanates. Both compounds can be result from enzyme catalyzed reactions due to plant tissue disruption by unit operations such as cutting, blending etc. (Bell et al., 2018; Fernandes, Guedes de Pinho, Valentäo, Pereira, \& Andrade, 2009). In kale leaves, Fernandes et al. (2009) reported the presence of 66 volatile compounds classified into alcohols, aldehydes, esters, ketones, norisoprenoid derivatives, terpenes, sulfur- and nitrogencontaining compounds.

As mentioned earlier, the complex GC-MS data were analyzed with a sequence of data pre-processing techniques (AMDIS and MPP) (section 2.5). The dataset resulting from the MPP was analyzed using MVDA to compare the impact of the different processing and storage effects. Firstly, PCA was utilized to detect any potential outliers, followed by PLS-DA, where the headspace volatiles of the purée samples were considered as $X$-variables and each sample (untreated and the processed samples before and after storage) as categorical $Y$-variables. In what follows, three detailed evaluations were performed: (i) an overall comparison over all kale purée treatments including storage; (ii) a detailed 
comparison among different thermal processing intensities (TP70, TP90 and TP128); and (iii) a detailed comparison between non stored and stored samples for each of the processing intensities.

\subsubsection{Investigation of the quality changes over_all kale purée samples}

The overall impact of the different processes throughout storage was depicted in a PLS-DA biplot (Figure 3A). In the biplot, relationships between a treatment class and the volatiles that are typical for specific treatments can be visualized. Samples close to each other have more similar volatile profiles and volatiles situated close to a certain group of samples are positively correlated to the corresponding treatment(s). Here, the non-stored samples (untreated, TP70, and TP90) are closely related (showing little differences) while the stored TP70 and stored TP128 samples are clearly separated from the other samples (including their non-stored counterparts). However, only $31 \%$ of the $Y$-variance can be explained by the first two LVs, and given the short length of the vectors, it is clear that no definite separation between the untreated and the treated and stored samples could be determined by using only the first two LVs. In this case, 8 LV's were needed to explain $92 \%$ of the Y-variance. Therefore, classification of the volatiles was verified by the VID procedure. By this, the volatiles are ranked according to a VID coefficient in which their concentrations within the different classes are compared and valued between -1 and +1 . In this work, volatiles selected as discriminant are further identified based on available mass spectral libraries and their retention indices (Figure 3A (bold open circles) and Table 2A). In addition, these compounds are plotted individually in Figure 4.

In Table 2A, the nine discriminant volatiles selected in kale purée (i.e. marker) can be categorized as nitrogen-containing compounds, sulfur-containing compounds, alcohols, aldehydes, Strecker aldehydes and furanic compounds. Only one component with higher concentration after the high-intensity treatment was selected as a marker (i.e. furanic compound), and eight were selected for stored processed samples. This observation confirms that of both processing and storage have an influence on the volatile compounds obtained. Therefore, in the next section, the impact of increasing processing intensity and the impact of storage on volatile changes of kale purée are further discussed in detail. In a similar way, models were built, bi-plots were constructed and markers were selected for the individual effects to be investigated. In addition, it is of interest to better understand the possible reasons behind these differences (in terms of their volatile profiles due to treatment or storage) by linking these selected markers with different reaction pathways described in literature.

\subsubsection{Effect of increasing thermal processing intensity}

\subsubsection{Visualization of the processing intensity impact differences}

In Figure 3B, a biplot representing the impact of increasing thermal processing intensity in detail is shown. Here, the bi-plot showed a clear separation between the untreated class and the different thermal classes (TP70, TP90, and TP128). It can be observed as well that there was a "slight effect" of increasing processing intensity in the direction of the horizontal axis, as indicated by the first LV $130.5 \%$ $Y$-variance explained). However, using only the first two LVs, explaining 55\% of $Y$-variance, and taking into account the vectors' length, it is difficult to state that one class is more similar/different to the other classes. In this case, higher LVs should be added to the model because those may still contain 
additional important information. Hence, five LVs were needed to explain $93 \%$ of the class variance for the intensity comparison.

\subsubsection{Quantitative selection of discriminant headspace markers and interpretation of the identity of the selected markers}

In the next step, volatiles that showed significance for differentiation between the treatments were selected through calculation of VID coefficients; they are listed in Table 2B. While no compound was selected for control and TP70, six compounds were selected for higher intensity TP treatments (one and five markers for TP90 and TP128, respectively). A number of components formed (the ones with positive VID coefficients) as a result of the increasing processing intensity were thiocyanates, sulfurcontaining compounds, and furans.

One thiocyanate (ATC) was selected as the marker for TP90. The concentration of ATC was the highest at TP90 ( $p<0.05)$, followed by TP70, TP128 and untreated samples (see Figure 4). ATC is produced by the hydrolysis of its parent glucosinolate by myrosinase (Ghawi, Methven, \& Niranjan, 2013; Bell et al., 2018) and it can be generated as well from allyl isothiocyanate (AITC) when subjected to high temperature (Chen \& Ho, 1998). As mentioned earlier, disruption of plant tissues upon crushing or cutting will bring myrosinase in contact with its substrate, hence, glucosinolates will be hydrolysed. The nature of the hydrolytic products formed (isothiocyanates, nitriles, epithionitriles, oxazolidines, and thiocyanates) depends on the structure of the parent glucosinolate compound and the environmental conditions such as $\mathrm{pH}$, co-factors like $\mathrm{Fe}^{2+}$ as well as the presence of specifier proteins such as epithiospecifier protein (ESP), nitrile specifier protein (NSP), and thiocyanate-forming protein (TFP) (Ghawi, Methven, \& Niranjan, 2013; Bell et al., 2018). In the study by Matusheski, Juvik, and Jeffery (2004), heating broccoli florets and sprouts to $60^{\circ} \mathrm{C}$ for 5-10 min caused a significant decrease in ESP activity, as a consequence, the formation of sulforaphane nitrile was reduced; however, an increase in sulforaphane, an isothiocyanate, was observed. The temperature sensitivity of ESP might explain the higher formation of thiocyanates upon mild heating in the current study. On the other hand, heating to $100{ }^{\circ} \mathrm{C}$ resulted in a significant decrease in total hydrolytic products, sulforaphane nitrile and sulforaphane (Matusheski, et al., 2004). Moreover, sulfur containing compounds can be formed through thermal degradation of sulforaphane (Jin et al., 1999). Thus, it is likely that treatment at $128{ }^{\circ} \mathrm{C}$ degraded the hydrolytic products such as isothiocyanates and thiocyanates and, correspondingly, facilitated the formation of sulfur containing compounds.

Figure 4 shows furans (2-pentenyl furan and 2-pentyl furan) and sulfides (dimethyl sulfide, dimethyl disulfide, and methyl (methylthio)methyl disulfide) were found in higher concentration in TP128. This finding suggests that the formation of furan and sulfur containing compounds is significantly influenced by thermal treatment. It was reported that the formation of these compounds is a result of interacting, complex reaction mechanisms rather than a single step. The presence of furan and its derivatives in thermally processed foods has been linked to different potential precursors such as polyunsaturated fatty acids, carotenoids, sugars, amino acids, and AA (Palmers et al., 2015). Furan and its derivatives are important volatiles contributing to roasted, burnt, caramel-like, sweet, and bitter aroma of thermally processed foods (Pico, Bernal, \& Gómez, 2015). 
Multiple routes of sulfur containing compound formation have been mentioned in literature, they include (combined) enzymatic pathways and chemical pathways due to thermal processing. Spadone, Matthey-Doret, and Blank (2006) reported that disruption of the broccoli cells, due to cutting, activates cysteine sulfoxide lyase transforming methylcysteine sulfoxide (MCSO) into methylsufenic acid, which during thermal treatment enhances the production of methyl (methylthio)methyl disulfide. Dimethyl disulfide and dimethyl trisulfide can be also derived from MCSO (Engel et al., 2002; Tulio, Yamanaka, Ueda, \& Imahori, 2002). Processing conditions (time and temperature) appear to play an important role in the formation of these compounds. Barrett et al. (2008) observed no detectable levels of dimethyl sulfide in either unblanched broccoli florets or those blanched for $45 \mathrm{~s}$; however, it was detectable at longer blanching times (90-180s). Others reported that thermal degradation of sulforaphane, an enzymatic degradation product of glucosinolates, generated higher concentrations of sulfur containing compounds (e.g. dimethyl disufide, methyl (methylthio)methyl disulfide, and 4isothiocyanato-1-(methylthio)-1-butene) at $100{ }^{\circ} \mathrm{C}$ than $50{ }^{\circ} \mathrm{C}$ (Jin, Wang, Rosen, \& Ho, 1999). Sulfur containing compounds such as methanethiol, dimethyl disulfide, dimethyl trisulfide have been considered as the major contributor to the sulfurous, cabbage aroma, and overcooked off-odors, due to their low odor threshold values (Bell et al., 2018; Engel et al., 2002).

\subsubsection{Effect of storage}

\subsubsection{Visualization of the storage impact differences}

The volatile profiles of non-stored and stored samples were compared in detail using a PLS-DA model. For each of the processing intensities, a biplot was constructed for qualitative graphical representations of scores and loadings, as can be seen in Figure $\mathbf{3 C}-\mathbf{1}, \mathbf{3 C}-\mathbf{2}$, and $\mathbf{3 C}-\mathbf{3}$ for changes during frozen-thawed, refrigerated, and ambient storage, respectively. In these biplots, the LV1 explained already a high amount of the $Y$-variance, more than $90 \%$. This signifies the differences between each of these two samples in terms of their volatile profiles. It is clear from the biplots that more volatiles are projected close to the stored samples, indicating more volatiles at higher concentrations in these samples. This statement holds for all storage conditions studied.

\subsubsection{Quantitative selection of discriminant headspace markers and interpretation of the identity} of the selected markers

Similar to the previous sections, VID coefficients were calculated to quantitatively rank the importance of the volatiles. Most of the selected volatiles showed a negative VID in non-stored TP70, TP90, and TP128 samples indicating higher concentrations in the stored samples (Table 2C, 2D, and 2E). Those compounds can be classified into terpene aldehydes, thiocyanates, alcohols, nitriles, ketones, furans, Strecker aldehydes and sulfur containing compounds.

In Figure 4, the concentration of one terpene aldehyde ( $\beta$-cyclocitral) is significantly higher in the stored samples compared to the non-stored classes. The formation of norisoprenoids, $\beta$-cyclocitral, $\alpha$-ionone, $\beta$-ionone, and $\beta$-damascenone, seems to be closely linked to the degradation of carotenoids. To be specific, $\beta$-cyclocitral is derived from oxidative cleavage of the double bond between carbons 7 and 8 of $\alpha$ - and $\beta$-carotene and carbons $7^{\prime}$ and $8^{\prime}$ of $\beta$-cryptoxanthin (Mahattanatawee, Rouseff, Valim, \& Naim, 2005). The carotenoids identified in kale leaves included neoxanthin, lutein, and all-trans- $\beta$ - carotene with total carotenoids being reported to vary from 181.3 to $1849.1 \mu \mathrm{g} / \mathrm{g}$ DW (Kim 
et al., 2017). Changes in carotenoids due to storage were reported by Korus (2013) who observed that the concentration of total carotenoids in cooked and blanched kale decreased by 10 to $11 \%$ after 12 months of frozen storage $\left(-20\right.$ to $\left.-30^{\circ} \mathrm{C}\right)$. It was reported that $\beta$-cyclocitral has mild floral, sweet and hay-like odor; this compound together with other norisoprenoids compounds contributed to around $8 \%$ of the total fresh orange juice aroma intensity (Mahattanatawee et al., 2005).

Formation of thiocyanates, alcohols, ketones, nitriles, and sulfur containing compounds during storage can be attributed to lipid oxidation, carotenoid degradation and enzyme catalyzed reactions, while the presence of Strecker aldehydes could be an indication of the Maillard reaction that was initiated during thermal processing and then continued during storage (Kebede et al., 2015; Tulio et al., 2002). In kale leaves, palmitic acid, linoleic acid, and $\alpha$-linolenic acid were reported as the major fatty acids (Ayaz et al., 2006) which could serve as precursors of volatile compounds. Degradation of fatty acids, occurring through enzymatic (oxidation via lipoxygenase) or non-enzymatic oxidation (e.g. autoxidation and thermally-induced oxidation), form hydroperoxides that subsequently break down into alcohols, alkanes, ketones and aldehydes (Christensen, Edelenbos, \& Kreutzmann, 2007).

In the study of Barrett (2008), lipoxygenase, peroxidase, and cysteine lyase of broccoli were inactivated after $90 \mathrm{~s}$ at blanching temperature $100{ }^{\circ} \mathrm{C}$. Similarly, lipoxygenase and peroxidase were inactivated under blanching temperature of $90^{\circ} \mathrm{C}$ for $3 \mathrm{~min}$, however, blanching at $70^{\circ} \mathrm{C}$ for 2 min resulted in $90 \%$ and 30\% inactivation of lipoxygenase and peroxidase, respectively (Bahçeci et al., 2005). Tulio et al. (2002) reported that freezing and thawing the broccoli florets had no significant impact on the activity of cysteine lyase. It is very likely that enzymatic reactions still occurred due to the presence of residual enzymatic activity in TP70 sample (section 3.1.1.2); therefore, fatty acid degradation volatiles (alcohols, ketones, and aldehydes) can still be produced under the storage conditions studied.

Myrosinase is another enzyme present in Brassica vegetables, its stability varying among different Brassica species. For example, in broccoli, a treatment at $90{ }^{\circ} \mathrm{C}$ for 4 min led to $80 \%$ reduction in myrosinase activity, while in green cabbage, a $83 \%$ decrease was achieved at $55{ }^{\circ} \mathrm{C}$ for 10 minutes (Ghawi et al., 2013; Ghawi, Methven, Rastall, \& Niranjan, 2012). Although not measured in this study, it can be assumed that myrosinase and cysteine lyase activity were still present in the TP70 samples. These enzymes may act on glucosinolates and (+)-S-methyl-L-cysteine sulfoxide (SMCSO). As a consequence, glucosinolate hydrolytic products (e.g. thiocyanates, isothiocyanates, and nitriles) and volatile sulfur containing compounds (e.g. dimethyl disulfide and dimethyl trisulfide) were formed. Finally, it needs to be mentioned that besides storage time and temperature, the impact of packaging on volatile profile changes during storage should not be overlooked (Wibowo et al. (2018).

\section{CONCLUSION}

The impact of different thermal processing intensities and storage on quality attributes of kale purée were investigated using an integrated targeted and untargeted approach. All treatments resulted in varying degrees of quality losses. With respect to the factors determining the product appearance, increasing process intensity clearly reduced the green color with substantial chlorophyll degradation to olive brown pigments at high-intensity TP-heated sample. Significant loss of vitamin C in varying degrees occurred after the treatments and continued during storage. In relation to the textural 
properties, no significant differences were observed in consistency after low- and medium-intensity treatments while the highest consistency coinciding with phase separation was observed after TP128 treatment. POD, PPO, and PME inactivation showed a similar trend with processing intensity, although POD appears to be more resistant than the other enzymes at the same treatment intensity. Concerning taste related compounds, acidity and sweetness were not affected by processing and all purées were relatively stable during subsequent storage.

The headspace volatile fraction largely changed with processing intensity and storge. In an overall comparison, one marker was associated with the TP128 class and eight markers were selected in the stored processed classes. This indicates that TP128 and storage increased the number and/or concentrations of volatile compounds compared to the non-processed material. Regarding the process intensity, sulfides, and furans formed in TP128 treatment could be breakdown products of several sulfur-containing amino acids, glucosinolates, sugars and AA due to the high temperature. During storage, higher concentrations of volatiles were generated compared to the non-stored sample. Depending on the processing and storage conditions used, this can be attributed to lipid and/or carotenoid oxidation, continuation of Maillard reactions, and enzyme catalysed reactions.

Given the complexity of chemical and bio-chemical changes that can occur during kale processing and subsequent storage, this study concludes that low-intensity thermal processing leads to products suffering from enzyme-catalyzed reactions during subsequent storage and high-intensity thermal processing leads to products with severe quality deterioration both during processing and ambient storage. An intermediate thermal process intensity seems the best choice to create a high quality kale product that is reasonably quality stable under refrigerated conditions.

\section{Acknowledgement}

The authors acknowledge the financial support of Flanders' Food under the HighQJuice project, including the stakeholders platform members involved.

\section{Declarations of interest}

The authors of the present work declare no conflict of interests.

\section{References}

Albanese, D., Russo, L., Cinquanta, L., Brasiello, A., \& Di Matteo, M. (2007). Physical and chemical changes in minimally processed green asparagus during cold-storage. Food Chemistry, 101, 274-280.

Armesto, J., Gómez-Limia, L., Carballo, J., \& Martínez, S. (2018). Effects of different cooking methods on the antioxidant capacity and flavonoid, organic acid and mineral contents of Galega Kale (Brassica oleracea var. acephala cv. Galega). International Journal of Food Sciences and Nutrition, 1-14. 
Armesto, J., Gómez-Limia, L., Carballo, J., \& Martìnez, S. (2017). Impact of vacuum cooking and boiling, and refrigerated storage on the quality of galega kale (Brassica oleracea var. acephala cv. Galega). LWT - Food Science and Technology, 79, 267-277.

Augustin, M. A., Riley, M., Stockmann, R., Bennett, L., Kahl, A., Lockett, T. et al. (2016). Role of food processing in food and nutrition security. Trends in Food Science \& Technology, 56, 115-125.

Ayaz, F. A., Glew, R. H., Millson, M., Huang, H. S., Chuang, L. T., Sanz, C. et al. (2006). Nutrient contents of kale (Brassica oleraceae L. var. acephala DC.). Food Chemistry, 96, 572-579.

Bahçeci, K. S., Serpen, A., Gökmen, V., \& Acar, J. (2005). Study of lipoxygenase and peroxidase as indicator enzymes in green beans: change of enzyme activity, ascorbic acid and chlorophylls during frozen storage. Journal of Food Engineering, 66, 187-192.

Barrett, D. M., Garcia, E. L., Russell, G. F., Ramirez, E., \& Shirazi, A. (2008). Blanch time and cultivar effects on quality of frozen and stored corn and broccoli. Journal of Food Science, 65, 534-540.

Bell, L., Oloyede, O. O., Lignou, S., Wagstaff, C., \& Methven, L. (2018). Taste and flavor perceptions of glucosinolates, isothiocyanates, and related compounds. Molecular Nutrition \& Food Research, 62, 1700990 .

Chen, C. W. \& Ho, C. T. (1998). Thermal degradation of allyl isothiocyanate in aqueous solution. Journal of Agricultural and Food Chemistry, 46, 220-223.

Christensen, L. P., Edelenbos, M., \& Kreutzmann, S. (2007). Fruits and vegetables of moderate climate. In R.G.Berger (Ed.), Flavours and Fragrances: Chemistry, Bioprocessing and Sustainability (pp. 135-187). Berlin, Heidelberg: Springer Berlin Heidelberg.

Davey, M. W., Montagu, M. V., Inzé, D., Sanmartin, M., Kanellis, A., Smirnoff, N. et al. (2002). Plant Lascorbic acid: chemistry, function, metabolism, bioavailability and effects of processing. Journal of the Science of Food and Agriculture, 80, 825-860.

Engel, E., Baty, C., le Corre, D., Souchon, I., \& Martin, N. (2002). Flavor-active compounds potentially implicated in cooked cauliflower acceptance. Journal of Agricultural and Food Chemistry, 50, 64596467.

Fernandes, F., Guedes de Pinho, P., Valentäo, P., Pereira, J. A., \& Andrade, P. B. (2009). Volatile Constituents throughout Brassica oleracea L. Var. acephala Germination. Journal of Agricultural and Food Chemistry, 57, 6795-6802.

Ghawi, S. K., Methven, L., \& Niranjan, K. (2013). The potential to intensify sulforaphane formation in cooked broccoli (Brassica oleracea var. italica) using mustard seeds (Sinapis alba). Food Chemistry, 138, $1734-1741$.

Ghawi, S. K., Methven, L., Rastall, R. A., \& Niranjan, K. (2012). Thermal and high hydrostatic pressure inactivation of myrosinase from green cabbage: A kinetic study. Food Chemistry, 131, 1240-1247.

Gökmen, V., Savas Bahçeci, K., Serpen, A., \& Acar, J. (2005). Study of lipoxygenase and peroxidase as blanching indicator enzymes in peas: change of enzyme activity, ascorbic acid and chlorophylls during frozen storage. LWT - Food Science and Technology, 38, 903-908.

Grauwet, T., Vervoort, L., Colle, I., Van Loey, A., \& Hendrickx, M. (2014). From fingerprinting to kinetics in evaluating food quality changes. Trends in Biotechnology, 32, 125-131. 
Jin, Y., Wang, M., Rosen, R. T., \& Ho, C. T. (1999). Thermal degradation of sulforaphane in aqueous solution. Journal of Agricultural and Food Chemistry, 47, 3121-3123.

Kebede, B. T., Grauwet, T., Magpusao, J., Palmers, S., Michiels, C., Hendrickx, M. et al. (2015). An integrated fingerprinting and kinetic approach to accelerated shelf-life testing of chemical changes in thermally treated carrot puree. Food Chemistry, 179, 94-102.

Kim, M. J., Chiu, Y.-C., \& Ku, K.-M. (2017). Glucosinolates, carotenoids, and vitamins E and K variation from selected kale and collard cultivars. Journal of Food Quality, 1-8.

Korus, A. (2013). Effect of preliminary and technological treatments on the content of chlorophylls and carotenoids in kale (Brassica oleracea L. var. acephala). Journal of Food Processing and Preservation, 37, 335-344.

López-Serrano, M. \& Ros Barceló, A. (2002). Comparative study of the products of the peroxidasecatalyzed and the polyphenoloxidase-catalyzed $(+)$-catechin oxidation. Their possible implications in strawberry (Fragaria $x$ ananassa) browning reactions. Journal of Agricultural and Food Chemistry, 50, 1218-1224.

Mahattanatawee, K., Rouseff, R., Valim, M. F., \& Naim, M. (2005). Identification and aroma impact of norisoprenoids in orange juice. Journal of Agricultural and Food Chemistry, 53, 393-397.

Martins, R. C. \& Silva, C. L. M. (2002). Modelling colour and chlorophyll losses of frozen green beans (Phaseolus vulgaris, L.). International Journal of Refrigeration, 25, 966-974.

Matusheski, N. V., Juvik, J. A., \& Jeffery, E. H. (2004). Heating decreases epithiospecifier protein activity and increases sulforaphane formation in broccoli. Phytochemistry, 65, 1273-1281.

Moelants, K. R. N., Jolie, R. P., Palmers, S. K. J., Cardinaels, R., Christiaens, S., Van Buggenhout, S. et al. (2013). The effects of process-induced pectin changes on the viscosity of carrot and tomato sera. Food and Bioprocess Technology, 6, 2870-2883.

Munyaka, A. W., Makule, E. E., Oey, I., Van Loey, A., \& Hendrickx, M. (2010). Thermal stability of Iascorbic acid and ascorbic acid oxidase in broccoli (Brassica oleracea var. italica). Journal of Food Science, 75, C336-C340.

Palmers, S., Grauwet, T., Celus, M., Wibowo, S., Kebede, B. T., Hendrickx, M. E. et al. (2015). A kinetic study of furan formation during storage of shelf-stable fruit juices. Journal of Food Engineering, 165, 74-81.

Pico, J., Bernal, J., \& Gómez, M. (2015). Wheat bread aroma compounds in crumb and crust: A review. Food Research International, 75, 200-215.

Rayan, A. M. M., Gab-Alla, A. A., Shatta, A. A., \& El-Shamei, Z. A. S. (2011). Thermal inactivation kinetics of quality-related enzymes in cauliflower (Brassica oleracea var. botrytis). European Food Research and Technology, 232, 319-326.

Šamec, D., Urlic, B., \& Salopek-Sondi, B. (2018). Kale (Brassica oleracea var. acephala) as a superfood: Review of the scientific evidence behind the statement. Critical Reviews in Food Science and Nutrition, $1-12$. 
Schmidt, S., Zietz, M., Schreiner, M., Rohn, S., Kroh, L. W., \& Krumbein, A. (2010). Genotypic and climatic influences on the concentration and composition of flavonoids in kale (Brassica oleracea var. sabellica). Food Chemistry, 119, 1293-1299.

Spadone, J. C., Matthey-Doret, W., \& Blank, I. (2006). Formation of methyl (methylthio)methyl disulfide in broccoli (Brassica oleracea (L.) var. italica). In W.L.P.Bredie \& M. A. Petersen (Eds.), Developments in Food Science-Flavour Science: Recent Advances and Trends (43 ed., pp. 309-314). Elsevier.

Terefe, N. S., Buckow, R., \& Versteeg, C. (2014). Quality-related enzymes in fruit and vegetable products: Effects of novel food processing technologies, Part 1: High-pressure processing. Critical Reviews in Food Science and Nutrition, 54, 24-63.

Tulio, A. Z., Yamanaka, H., Ueda, Y., \& Imahori, Y. (2002). Formation of methanethiol and dimethyl disulfide in crushed tissues of broccoli florets and their inhibition by freeze-thawing. Journal of Agricultural and Food Chemistry, 50, 1502-1507.

Van Buggenhout, S., Sila, D. N., Duvetter, T., Van Loey, A., \& Hendrickx, M. (2009). Pectins in processed fruits and vegetables: Part III-Texture engineering. Comprehensive Reviews in Food Science and Food Safety, 8, 105-117.

Verbeyst, L., Bogaerts, R., Van der Plancken, I., Hendrickx, M., \& Van Loey, A. (2013). Modelling of vitamin $C$ degradation during thermal and high-pressure treatments of red fruit. Food and Bioprocess Technology, 6, 1015-1023.

Vervoort, L., Van der Plancken, I., Grauwet, T., Timmermans, R. A. H., Mastwijk, H. C., Matser, A. M. et al. (2011). Comparing equivalent thermal, high pressure and pulsed electric field processes for mild pasteurization of orange juice: Part II: Impact on specific chemical and biochemical quality parameters. Innovative Food Science \& Emerging Technologies, 12, 466-477.

Weemaes, C. A., Ooms, V., Van Loey, A. M., \& Hendrickx, M. E. (1999). Kinetics of chlorophyll degradation and color loss in heated broccoli juice. Journal of Agricultural and Food Chemistry, 47, 2404-2409.

Wibowo, S., Buvé, C., Hendrickx, M., Van Loey, A., \& Grauwet, T. (2018). Integrated science-based approach to study quality changes of shelf-stable food products during storage: A proof of concept on orange and mango juices. Trends in Food Science \& Technology, 73, 76-86.

Wibowo, S., Grauwet, T., Santiago, J. S., Tomic, J., Vervoort, L., Hendrickx, M. et al. (2015). Quality changes of pasteurised orange juice during storage: A kinetic study of specific parameters and their relation to colour instability. Food Chemistry, 187, 140-151. 

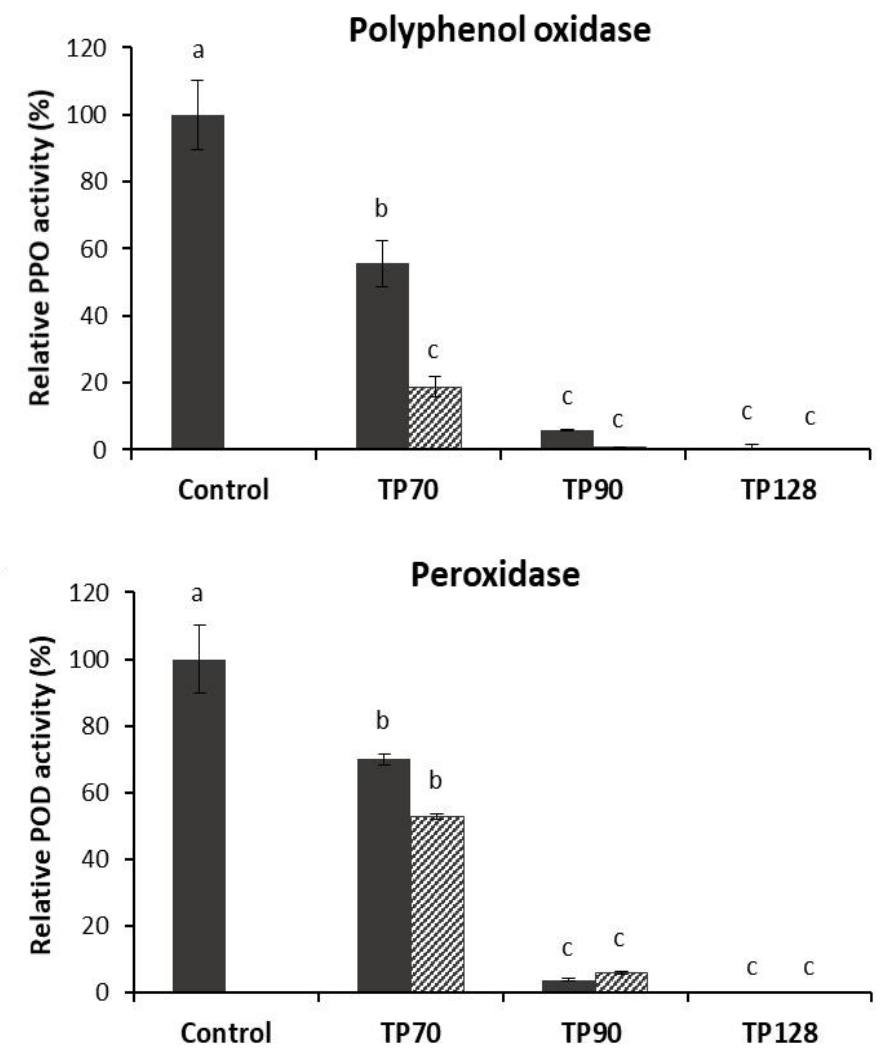

Total vitamin C

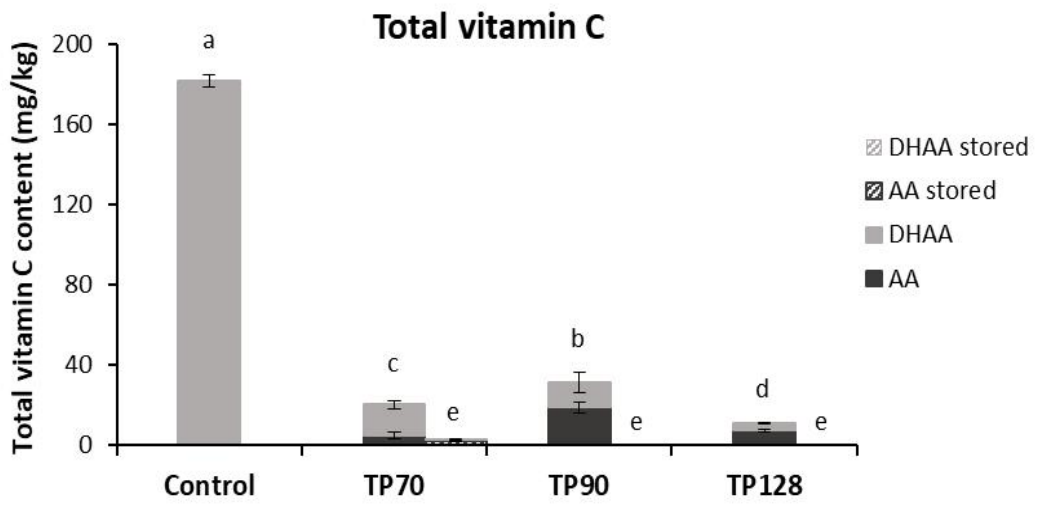

Figure 1. Relative PPO, POD and total vitamin C content of untreated and thermally processed (TP) kale purée samples before storage ( $\boldsymbol{\square})$ and after storage (TP70: 3 months of storage at $-20{ }^{\circ} \mathrm{C}$ and 2 days of storage at $4{ }^{\circ} \mathrm{C}$; TP90: 3 weeks of storage at $4{ }^{\circ} \mathrm{C}$; TP128: 3 months of storage at ambient temperature) (W//). Significant differences $(p<0.05)$ are indicated with different letters. 

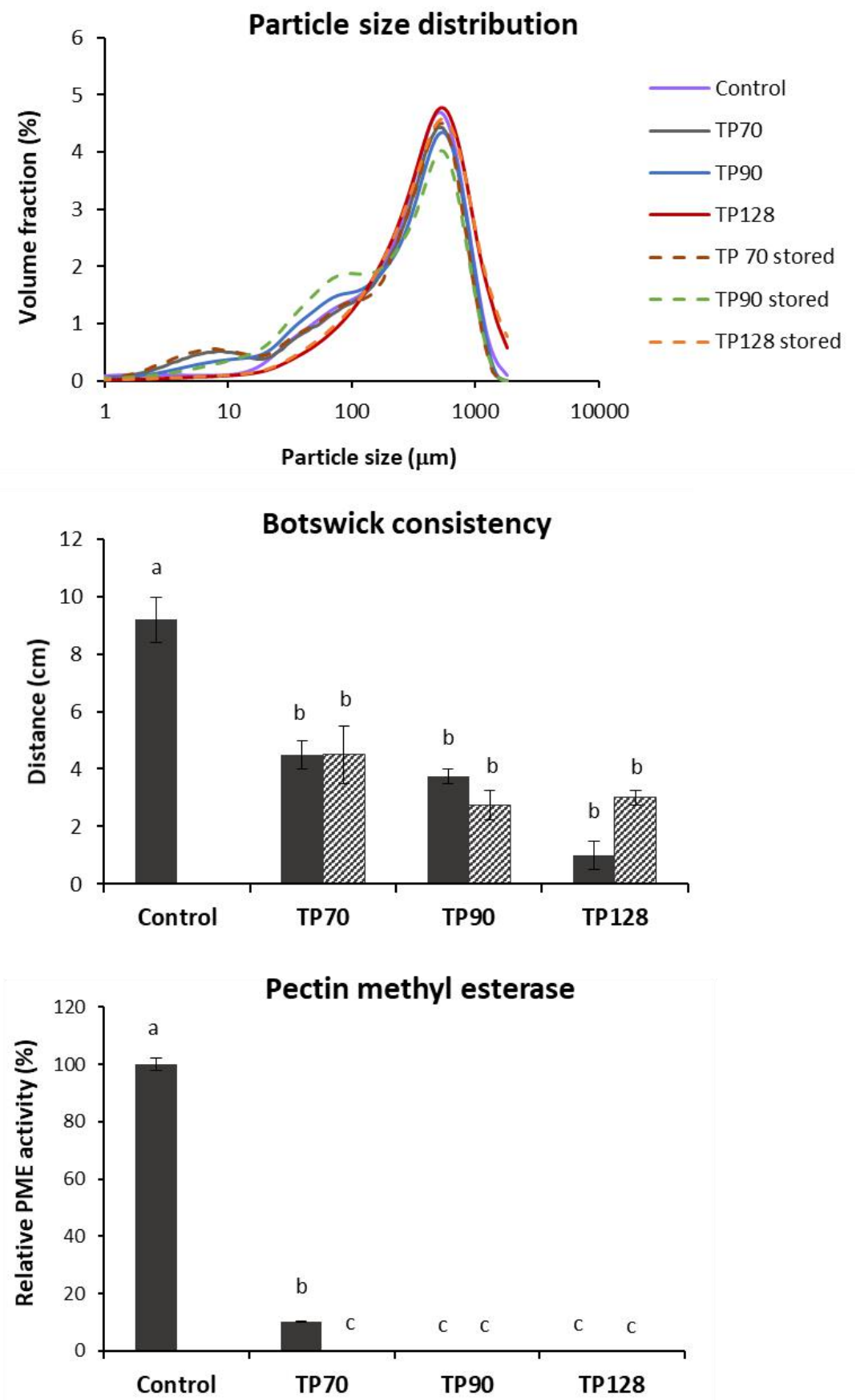

Figure 2. Volumetric particle size distribution, Bostwick consistency and residual PME of untreated and thermally processed (TP) kale purée samples before storage ( $\square$ ) and after storage (TP70: 3 months of storage at $-20^{\circ} \mathrm{C}$ and 2 days of storage at $4{ }^{\circ} \mathrm{C}$; TP90: 3 weeks of storage at $4{ }^{\circ} \mathrm{C}$; TP128: 3 months of storage at ambient temperature) ("//a). Significant differences $(p<0.05)$ are indicated with different letters. 

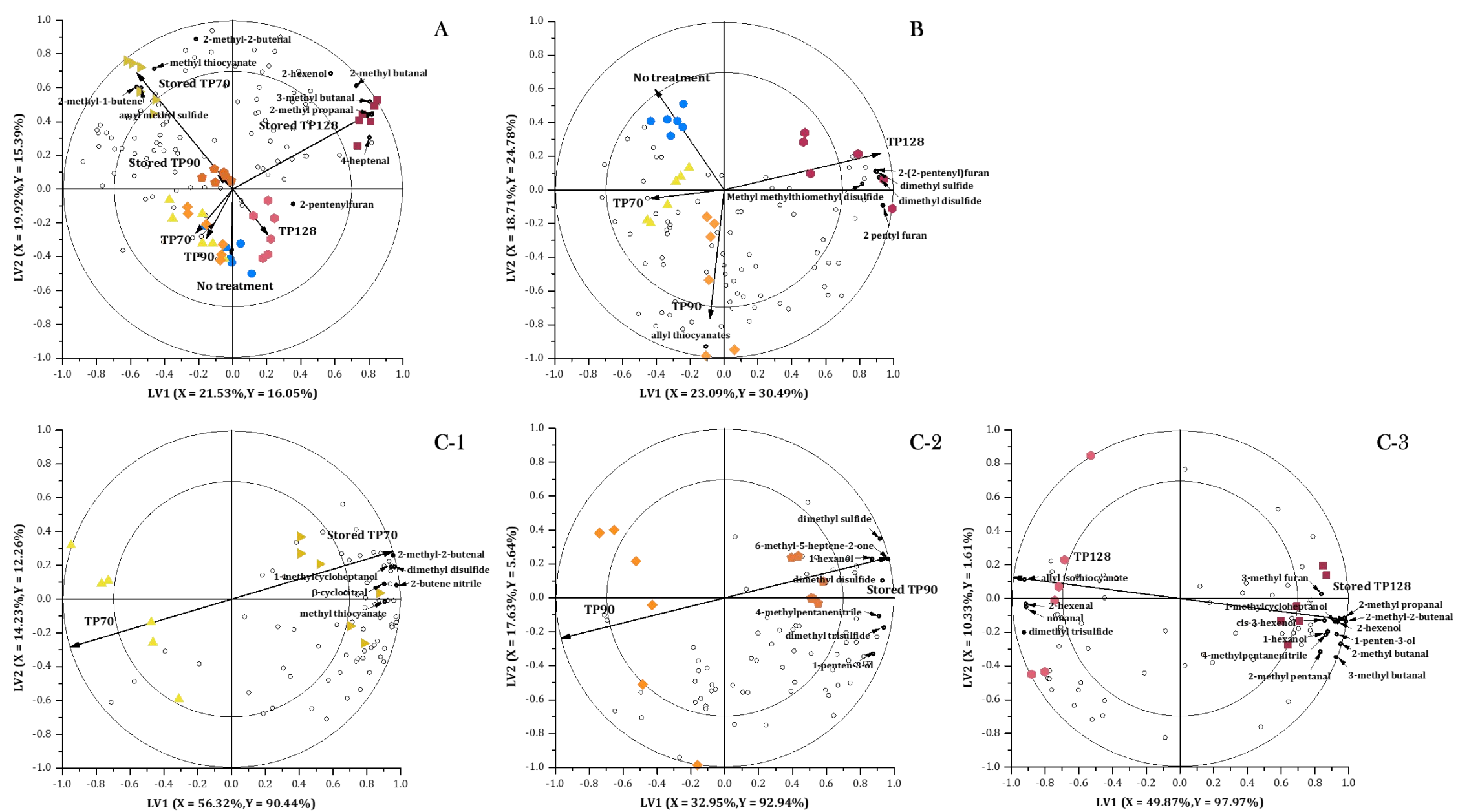

Figure 3. PLS-DA biplots describing the comparison over all kale purée treatments throughout storage (A), the comparison among different thermal processing intensities (B), the comparison between non stored and stored mild-intensity TP treatment at $70^{\circ} \mathrm{C}(\mathrm{C}-1)$, the comparison between non stored and stored medium-intensity TP treatment at $90{ }^{\circ} \mathrm{C}(\mathrm{C}-2)$, the comparison between non stored and stored high-intensity TP treatment at $128^{\circ} \mathrm{C}(\mathrm{C}-3)$. The open circles represent the different volatiles, of which only the compounds selected through the VID procedure are named (Table 2). Vectors indicate the correlation loadings for the categorical $Y$-variables. The percentages of the variances in $\mathrm{X}$ and $\mathrm{Y}$ explained by each latent variable (LV1 and LV2) are indicated on the respective axes. 

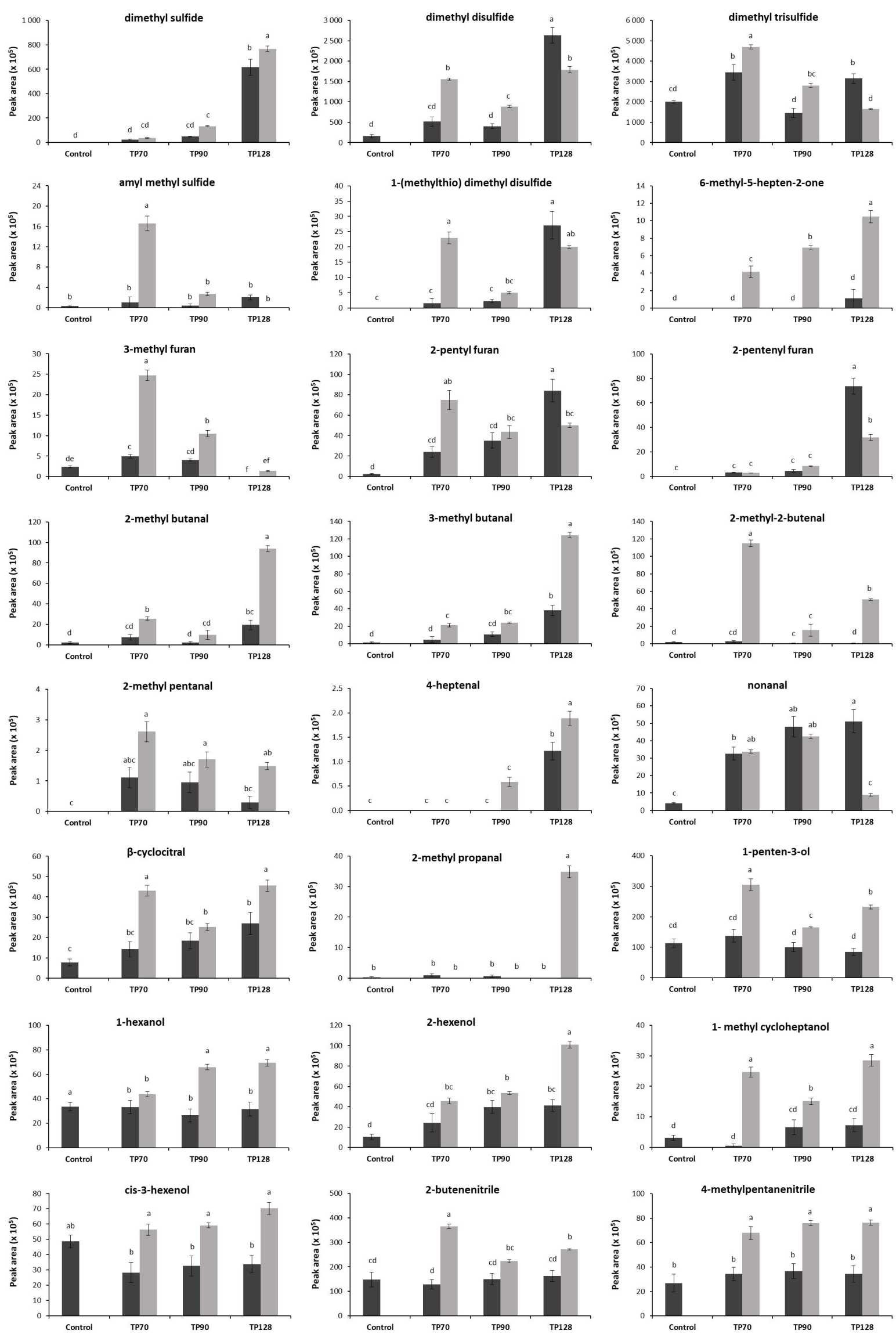
759
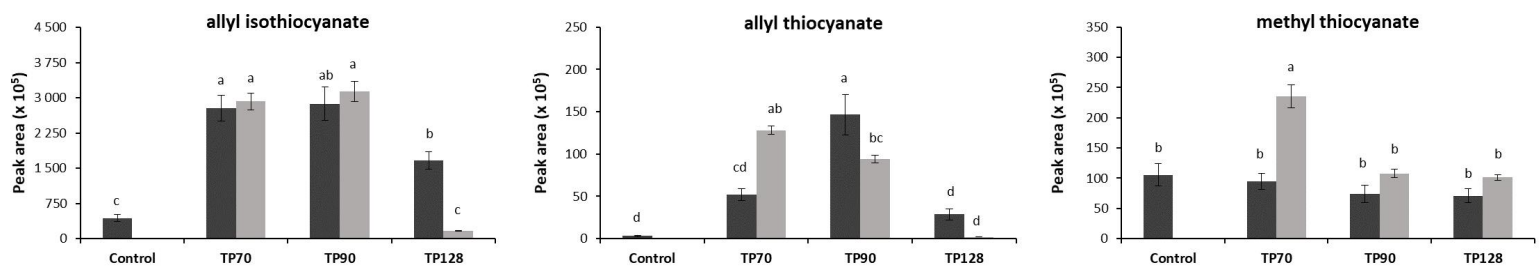

Figure 4. Discriminative headspace components selected through the VID procedure (Table 2) before storage ( $\mathbf{\square}$ ) and after storage (TP70: 3 months of storage at $-20^{\circ} \mathrm{C}$ and 2 days of storage at $4{ }^{\circ} \mathrm{C}$; TP90: 3 weeks of storage at 4 ${ }^{\circ} \mathrm{C}$; TP128: 3 months of storage at ambient temperature) ( $\square$ ). The $\mathrm{Y}$-axis indicates the peak area $\times 10^{5}$. Significant differences $(p<0.05)$ are indicated with different letters. Error bars represent the standard error of analysis $(\mathrm{n}=$ $6)$. 
Table 1. Color, chlorophyll, organic acid, and sugar contents of kale purée after treatments and during storage.

\begin{tabular}{|c|c|c|c|c|c|c|c|c|}
\hline \multirow{2}{*}{\multicolumn{2}{|c|}{ Physicochemical properties* }} & \multicolumn{4}{|l|}{ Before storage } & \multicolumn{3}{|l|}{ After storage*** } \\
\hline & & Control & TP70 & TP90 & TP128 & TP70 & TP90 & TP128 \\
\hline \multirow[t]{4}{*}{ Color } & $L^{*}$ & $23.44 \pm 0.09^{f}$ & $26.59 \pm 0.02^{c}$ & $27.25 \pm 0.04^{b}$ & $28.25 \pm 0.29^{a}$ & $26.47 \pm 0.09^{c}$ & $25.71 \pm 0.03^{d}$ & $24.06 \pm 0.10^{\mathrm{e}}$ \\
\hline & $a^{*}$ & $-13.83 \pm 0.01^{f}$ & $-12.68 \pm 0.06^{e}$ & $-12.58 \pm 0.02^{\mathrm{e}}$ & $-1.93 \pm 0.02^{b}$ & $-7.61 \pm 0.02^{d}$ & $-5.94 \pm 0.01^{c}$ & $1.85 \pm 0.01^{\mathrm{a}}$ \\
\hline & $b^{*}$ & $34.18 \pm 0.07^{c}$ & $35.86 \pm 0.08^{a}$ & $33.48 \pm 0.06^{d}$ & $27.81 \pm 0.27^{f}$ & $35.09 \pm 0.14^{b}$ & $31.46 \pm 0.05^{e}$ & $24.31 \pm 0.10^{g}$ \\
\hline & $\Delta E *$ & $-* *$ & $3.77 \pm 0.14^{\mathrm{e}}$ & $4.09 \pm 0.06^{\mathrm{e}}$ & $14.36 \pm 0.21^{\mathrm{b}}$ & $6.99 \pm 0.04^{d}$ & $8.67 \pm 0.02^{c}$ & $18.54 \pm 0.06^{\mathrm{a}}$ \\
\hline \multirow[t]{3}{*}{ Chlorophylls } & Chlorophyll a (mg/g) & $640.55 \pm 13.03^{a}$ & $481.61 \pm 11.55^{b c}$ & $532.28 \pm 23.03^{b}$ & $260.09 \pm 14.27^{d}$ & $438.81 \pm 1.96^{c}$ & $517.14 \pm 19.27^{b c}$ & $271.55 \pm 12.67^{d}$ \\
\hline & Chlorophyll b (mg/g) & $275.72 \pm 4.00^{\mathrm{a}}$ & $270.81 \pm 16.30^{\mathrm{a}}$ & $242.59 \pm 9.72^{\mathrm{a}}$ & $109.20 \pm 4.99^{b}$ & $264.17 \pm 3.82^{\mathrm{a}}$ & $126.59 \pm 14.97^{b}$ & $57.45 \pm 3.53^{c}$ \\
\hline & Total chlorophyll (mg/g) & $916.27 \pm 16.99^{a}$ & $752.42 \pm 5.44^{\mathrm{b}}$ & $774.87 \pm 32.75^{b}$ & $369.29 \pm 19.21^{d}$ & $702.98 \pm 4.78^{\mathrm{bc}}$ & $643.73 \pm 21.73^{c}$ & $329.00 \pm 16.13^{d}$ \\
\hline \multirow[t]{5}{*}{ Organic acids } & $\mathrm{pH}$ & $5.52 \pm 0.03^{b}$ & $5.46 \pm 0.01^{\text {cd }}$ & $5.58 \pm 0.01^{\mathrm{a}}$ & $5.49 \pm 0.01^{b c}$ & $5.41 \pm 0.01^{d}$ & $5.48 \pm 0.01^{b c}$ & $5.32 \pm 0.01^{\mathrm{e}}$ \\
\hline & Oxalic acid (g/L) & $11.14 \pm 0.03^{\mathrm{a}}$ & $10.11 \pm 0.08^{b c}$ & $9.83 \pm 0.05^{\mathrm{bcd}}$ & $9.56 \pm 0.75^{d}$ & $10.34 \pm 0.21^{\mathrm{ab}}$ & $9.98 \pm 0.04^{\mathrm{bc}}$ & $9.47 \pm 0.06^{c d}$ \\
\hline & Malic acid (g/L) & $5.05 \pm 0.01^{a}$ & $4.35 \pm 0.22^{\mathrm{a}}$ & $4.64 \pm 0.06^{a}$ & $4.60 \pm 0.04^{a}$ & $4.49 \pm 0.31^{a}$ & $5.06 \pm 0.17^{a}$ & $5.04 \pm 0.31^{\mathrm{a}}$ \\
\hline & Citric acid (g/L) & $2.11 \pm 0.01^{\mathrm{a}}$ & $1.79 \pm 0.07^{b}$ & $1.97 \pm 0.03^{\mathrm{ab}}$ & $1.81 \pm 0.01^{b}$ & $1.90 \pm 0.09^{b}$ & $1.98 \pm 0.01^{a b}$ & $1.86 \pm 0.03^{b}$ \\
\hline & Total acids (g/L) & $18.30 \pm 0.01^{\mathrm{a}}$ & $16.12 \pm 0.18^{b c}$ & $16.44 \pm 0.14^{b c}$ & $15.51 \pm 0.36^{c}$ & $16.73 \pm 0.02^{b}$ & $17.03 \pm 0.17^{b}$ & $16.37 \pm 0.35^{\mathrm{bc}}$ \\
\hline \multirow[t]{5}{*}{ Sugars } & TSS ( ${ }^{\circ}$ Brix $)$ & $12.33 \pm 0.14^{\mathrm{a}}$ & $10.59 \pm 0.04^{b}$ & $10.11 \pm 0.04^{\text {cd }}$ & $10.33 \pm 0.02^{b c}$ & $10.24 \pm 0.02^{c}$ & $9.91 \pm 0.17^{d}$ & $10.17 \pm 0.35^{\mathrm{cd}}$ \\
\hline & Fructose (g/L) & $6.46 \pm 0.09^{a}$ & $6.55 \pm 0.31^{a}$ & $5.93 \pm 0.10^{\mathrm{ab}}$ & $5.69 \pm 0.09^{b}$ & $6.54 \pm 0.16^{a}$ & $5.71 \pm 0.04^{b}$ & $5.59 \pm 0.06^{b}$ \\
\hline & Glucose $(\mathrm{g} / \mathrm{L})$ & $6.20 \pm 0.13^{a}$ & $4.83 \pm 0.18^{c}$ & $5.41 \pm 0.09^{b}$ & $5.14 \pm 0.10^{b c}$ & $4.91 \pm 0.11^{c}$ & $5.26 \pm 0.03^{b c}$ & $5.10 \pm 0.04^{b c}$ \\
\hline & Sucrose $(\mathrm{g} / \mathrm{L})$ & $5.05 \pm 0.08^{\mathrm{a}}$ & $4.44 \pm 0.17^{\mathrm{bc}}$ & $5.13 \pm 0.06^{a}$ & $5.02 \pm 0.06^{\mathrm{a}}$ & $4.30 \pm 0.12^{c}$ & $4.85 \pm 0.02^{\mathrm{ab}}$ & $4.96 \pm 0.03^{\mathrm{a}}$ \\
\hline & Total sugars $(\mathrm{g} / \mathrm{L})$ & $17.71 \pm 0.30^{\mathrm{a}}$ & $15.82 \pm 0.66^{b}$ & $16.47 \pm 0.24^{\mathrm{ab}}$ & $15.86 \pm 0.25^{b}$ & $15.75 \pm 0.37^{b}$ & $15.82 \pm 0.08^{b}$ & $15.65 \pm 0.11^{b}$ \\
\hline
\end{tabular}

* Values are means and standard errors of three determinations. Values with the different letters within one row are significantly different ( $p<0.05)$.

** The untreated kale purée is used as a reference to calculate $\Delta E^{*}$.

*** TP70: 3 months of storage at $-20^{\circ} \mathrm{C}$ and 2 days of storage at $4{ }^{\circ} \mathrm{C}$; TP90: 3 weeks of storage at $4{ }^{\circ} \mathrm{C} ;$ TP $128: 3$ months of storage at ambient temperature 
Table 2. Discriminant headspace components in kale purée selected through the VID procedure according to the effect studied: A. comparing the iimpact of processing and storage altogether; B. comparing the effect of increasing processing intensity; and C. comparing the impact of storage. The compounds are listed in decreasing order of absolute VID value, where a positive VID value indicates a higher concentration of a compound for that class compared to others and negative value lower concentration compared to other classes. The retention index (RI) and chemical group are listed for proof of identity.

\begin{tabular}{lclll}
\hline Treatment & VID* & Identity & RI & Chemical group \\
\hline A. The overall comparison & & & \\
\hline Control (untreated) & n.d. & & \\
TP70 & n.d. & & \\
TP90 & n.d. & & \\
TP128 & 0.85 & 2-pentenylfuran & 2308 & Furanic compound \\
TP70 stored & 0.86 & 2-methyl-2-butenal & 1599 & Aldehyde (Strecker) \\
& 0.85 & amyl methyl sulfide & 1671 & Sulfur compound \\
TP90 stored & 0.85 & methyl thiocyanate & 2195 & Thiocyanate \\
TP128 stored & n.d. & & & \\
& 0.97 & 2-methyl propanal & 1067 & Aldehyde (Strecker) \\
& 0.95 & 3-methylbutanal & 1199 & Aldehyde (Strecker) \\
& 0.94 & 2-methylbutanal & 1192 & Aldehyde (Strecker) \\
& 0.84 & 4-heptenal & 2075 & Aldehyde \\
\hline
\end{tabular}

\begin{tabular}{|c|c|c|c|c|}
\hline \multicolumn{5}{|c|}{ B. The effect of increasing thermal processing intensity } \\
\hline \multicolumn{5}{|c|}{ Control (untreated) $\quad$ n.d. } \\
\hline TP70 & n.d. & & & \\
\hline TP90 & 0.90 & allyl thiocyanate & 2939 & Thiocyanate \\
\hline \multirow{5}{*}{ TP128 } & 0.94 & dimethyl disulfide & 1543 & Sulfur compound \\
\hline & 0.92 & trans-2-pentenylfuran & 2308 & Furanic compound \\
\hline & 0.89 & 2-pentylfuran & 2034 & Furanic compound \\
\hline & 0.89 & dimethyl sulfide & 1023 & Sulfur compound \\
\hline & 0.84 & methyl methylthiomethyl disulfide & 3628 & Sulfur compound \\
\hline \multicolumn{5}{|c|}{ C-1. The effect of frozen-thawed storage for TP70 samples } \\
\hline \multirow[t]{7}{*}{ TP70 } & -0.81 & $\beta$-cyclocitral & 3505 & Terpene (aldehyde) \\
\hline & -0.81 & methyl thiocyanate & 2195 & Thiocyanate \\
\hline & -0.83 & 1-methylcycloheptanol & 3444 & Alcohol \\
\hline & -0.84 & 2-butenenitrile & 1858 & Nitrile \\
\hline & -0.84 & 2-methyl-2-butenal & 1599 & Aldehyde (Strecker) \\
\hline & -0.85 & dimethyl disulfide & 1545 & Sulfur compound \\
\hline & 0.84 & methyl methylthiomethyl disulfide & 3628 & Sulfur compound \\
\hline \multicolumn{5}{|c|}{ C-2. The effect of refrigerated storage for TP90 samples } \\
\hline \multirow[t]{7}{*}{ TP90 } & -0.80 & 1-penten-3-ol & 1780 & Alcohol \\
\hline & -0.88 & 4-methylpentanenitrile & 2088 & Nitrile \\
\hline & -0.89 & dimethyl trisulfide & 2645 & Sulfur compound \\
\hline & -0.90 & 1-hexanol & 2497 & Alcohol \\
\hline & -0.93 & dimethyl disulfide & 1544 & Sulfur compound \\
\hline & -0.96 & dimethyl sulfide & 1023 & Sulfur compound \\
\hline & -0.99 & 6-methyl-5-heptene-2-one & 2452 & Ketone \\
\hline \multicolumn{5}{|c|}{ C-3. The effect of ambient storage for TP128 samples } \\
\hline \multirow[t]{15}{*}{ TP128 } & 0.93 & allyl isothiocyanate & 2560 & Thiocyanate \\
\hline & 0.91 & dimethyl trisulfide & 2645 & Sulfur compound \\
\hline & 0.91 & 2-hexenal & 1989 & Aldehyde \\
\hline & 0.91 & nonanal & 2669 & Aldehyde \\
\hline & -0.84 & 3-methylfuran & 1165 & Furanic compound \\
\hline & -0.85 & 2-methylpentanal & 1305 & Aldehyde (Strecker) \\
\hline & -0.86 & cis-3-hexenol & 2633 & Alcohol \\
\hline & -0.88 & 4-methylpentanenitrile & 2088 & Nitrile \\
\hline & -0.89 & 1-hexanol & 2497 & Alcohol \\
\hline & -0.94 & 1-penten-3-ol & 1781 & Alcohol \\
\hline & -0.94 & 2-hexenol & 2364 & Alcohol \\
\hline & -0.94 & 3-methylbutanal & 1199 & Aldehyde (Strecker) \\
\hline & -0.97 & 2-methylbutanal & 1192 & Aldehyde (Strecker) \\
\hline & -0.98 & 2-methyl propanal & 1067 & Aldehyde (Strecker) \\
\hline & -0.99 & 2-methyl-2-butenal & 1600 & Aldehyde (Strecker) \\
\hline
\end{tabular}

* n.d. = no volatile compound detected that met the requirements of the VID procedure 
Supplementary 1. Microbiology results of kale puree before and after treatments (CFU/ml).

\begin{tabular}{lllll}
\hline & Control $^{1)}$ & TP70 & TP90 & TP128 \\
\hline Listeria spp $^{2)}$ & present & not present & not present & not present \\
Listeria monocytogenes $^{2)}$ & present & not present & not present & not present \\
Total aerobic mesophilic & $6.6^{*} 10^{7}$ & $1.2^{*} 10^{6}$ & $7.5^{*} 10^{3}$ & $<10^{3)}$ \\
Total anaerobic mesophilic & $4.9 * 10^{3}$ & $2.1^{*} 10^{2}$ & $1.9 * 10^{3}$ & $<10$ \\
Aerobic sporeforming bacteria & $8.8^{*} 10^{3}$ & $4.3^{*} 10^{3}$ & $1.9 * 10^{3}$ & $<10$ \\
Anaerobic sporeforming bacteria & $4.9 * 10^{2}$ & $1.6^{*} 10^{2}$ & $7.7 * 10^{2}$ & $1.8^{*} 10^{1}$ \\
Total aerobic psychrotrophic bacteria & $9.4 * 10^{7}$ & $8.8^{*} 10^{5}$ & $1.1^{*} 10^{4}$ & - \\
Lactic acid bacteria & $4.9 * 10^{3}$ & $<10$ & $<10$ & - \\
Yeast & $4.7 * 10^{2}$ & $<10$ & $<10$ & - \\
Mold & $3.6^{*} 10^{3}$ & $<10$ & $<10$ & - \\
Enterobacteriaceae & $4.1 * 10^{3}$ & $<10$ & $<10$ & - \\
\hline
\end{tabular}

\footnotetext{
1) Control is the untreated sample.

2) If one repetition is present, the average is present

3) The values $<10$ represent detection limit
}

Supplementary 2. Visual appearance of untreated and thermally processed (TP) kale purée samples before storage.

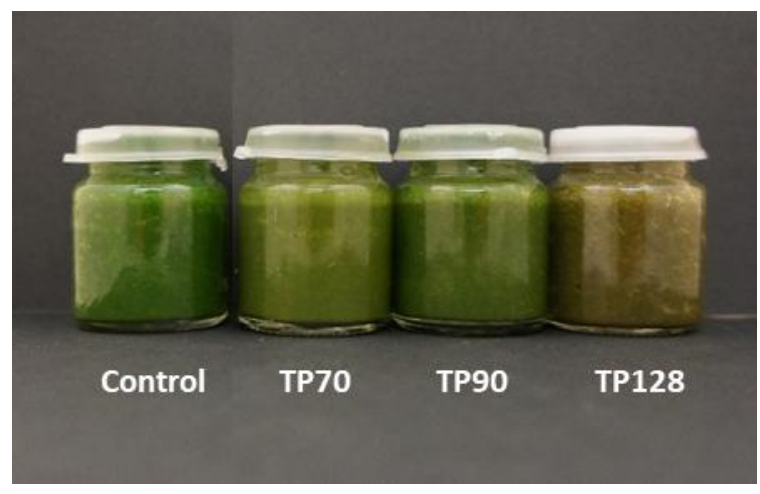

Supplementary 3. Particle size of the kale purée expressed as the size of which 10,50 or 90 vol\% of the particles have a smaller diameter (D10, D50 and D90).

\begin{tabular}{llll}
\hline Treatment & D10 $(\mu \mathrm{m})$ & D50 $(\mu \mathrm{m})$ & D90 $(\mu \mathrm{m})$ \\
\hline Before storage & & & \\
\hline Control & $47.76 \pm 2.15^{\mathrm{b}}$ & $363.15 \pm 7.28^{\mathrm{b}}$ & $912.51 \pm 41.60^{\mathrm{b}}$ \\
TP70 & $19.13 \pm 1.08^{\mathrm{d}}$ & $321.12 \pm 4.37^{\mathrm{c}}$ & $813.81 \pm 13.78^{\mathrm{bc}}$ \\
TP90 & $33.64 \pm 0.68^{\mathrm{c}}$ & $311.40 \pm 2.62^{\mathrm{c}}$ & $855.10 \pm 9.61^{\mathrm{bc}}$ \\
TP128 & $86.82 \pm 3.12^{\mathrm{a}}$ & $427.24 \pm 10.06^{\mathrm{a}}$ & $1036.70 \pm 22.26^{\mathrm{a}}$ \\
\hline After storage* & & & \\
\hline TP70 & $14.43 \pm 0.96^{\mathrm{d}}$ & $306.16 \pm 10.59^{\mathrm{c}}$ & $788.17 \pm 4.88^{\mathrm{c}}$ \\
TP90 & $29.33 \pm 0.34^{\mathrm{c}}$ & $258.94 \pm 2.53^{\mathrm{d}}$ & $787.32 \pm 9.60^{\mathrm{c}}$ \\
TP128 & $79.66 \pm 1.02^{\mathrm{a}}$ & $423.36 \pm 2.40^{\mathrm{a}}$ & $1069.04 \pm 13.43^{\mathrm{a}}$ \\
\hline
\end{tabular}

Values are means and standard errors of four determinations. Values with the different letters within one column are significantly different $(p<0.05)$.

${ }^{*}$ TP70: 3 months of storage at $-20^{\circ} \mathrm{C}$ and 2 days of storage at $4{ }^{\circ} \mathrm{C}$; TP90: 3 weeks of storage at $4{ }^{\circ} \mathrm{C} ;$ TP128: 3 


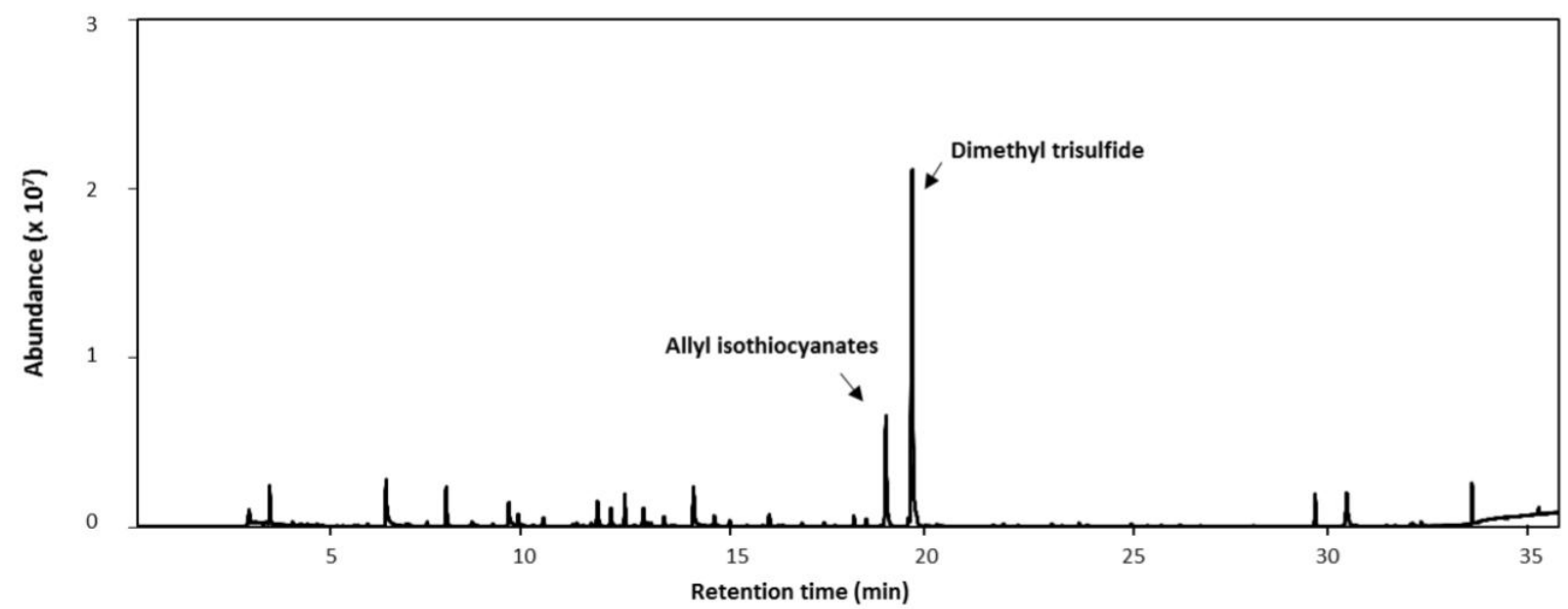

Supplementary 4. Total ion chromatogram of the headspace of untreated kale purée at the beginning of storage (week 0), obtained by headspace solid-phasemicroextraction GC-MS (HS-SPME-GC-MS) fingerprinting. 